\title{
Susceptibility to Kindling and Neuronal Connections of the Anterior Claustrum
}

\author{
Xia Zhang, ${ }^{1}$ Darren K. Hannesson, ${ }^{2}$ Deborah M. Saucier, ${ }^{2}$ Amy E. Wallace, ${ }^{2}$ John Howland, ${ }^{2}$ and \\ Michael E. Corcoran ${ }^{1,2}$ \\ ${ }^{1}$ Neuropsychiatry Research Unit, Department of Psychiatry, and 2Department of Psychology, University of Saskatchewan, \\ Saskatoon, Saskatchewan, Canada S7N 5E4
}

The claustrum has been implicated in the kindling of generalized seizures from limbic sites. We examined the susceptibility of the anterior claustrum itself to kindling and correlated this with an anatomical investigation of its afferent and efferent connections.

Electrical stimulation of the anterior claustrum resulted in a pattern of rapid kindling with two distinct phases. Early kindling involved extremely rapid progression to bilaterally generalized seizures of short duration. With repeated daily kindling stimulations, early-phase generalized seizures abruptly became more elaborate and prolonged, resembling limbic-type seizures as triggered from the amygdala. We suggest that the rapid rate of kindling from the anterior claustrum is an indication that the claustrum is functionally close to the mechanisms of seizure generalization.

The claustrum is a thin column of gray matter in the rostral half of the forebrain between the basal ganglia and cortex (Kowianski et al., 1999). The functions of the claustrum are unclear, although data suggest that it may be involved in coordination of sensorimotor or motor control (Olson and Graybiel, 1980; Crescimanno et al., 1989; Salerno et al., 1989; Cortimiglia et al., 1991; Shima et al., 1996), voluntary swallowing (Zald and Pardo, 1999), nociception (Sloniewski et al., 1995; Persinger et al., 1997), and conditioned fear (Beck and Fibiger, 1995), and may become pathological in Alzheimer's disease or aging (Ogomori et al., 1989; Morys et al., 1994, 1996a,b) and Parkinson's disease (Yoshimura et al., 1988).

Recent studies suggest that the claustrum may play an important role in epileptiform activity. Thus Kudo and Wada (1990) found that electrolytic lesions of the cat anterior claustrum ipsilateral to the kindled amygdala degraded generalized kindled seizures to partial seizures and retarded kindling. Similar results have also been observed in monkeys (Wada and Tsuchimochi, 1997). Radio-frequency (RF) lesions of the posterior claustrum delay amygdaloid kindling in rats (Mohapel et al., 2001). The results are not conclusive, however, because electrolytic and RF

\footnotetext{
Received Oct. 9, 2000; revised March 2, 2001; accepted March 6, 2001.

This research was supported by a grant from the Canadian Institutes of Health Research awarded to M.E.C. and by an Establishment Grant from the Health Services Utilization and Research Commission of Saskatchewan awarded to X.Z. We thank Yan Li for technical assistance.

Correspondence should be addressed to Dr. Michael Corcoran, Office of Research Services, Kirk Hall Room 217, University of Saskatchewan, 117 Science Place, Saskatoon, Saskatchewan, Canada S7N 5C8. E-mail: corcoran@ admin.usask.ca.

Copyright (C) 2001 Society for Neuroscience $\quad 0270-6474 / 01 / 213674-14 \$ 15.00 / 0$
}

In support of our hypothesis, we found significant afferent, efferent, and often reciprocal connections between the anterior claustrum and areas that have been implicated in the generation of generalized seizures, including frontal and motor cortex, limbic cortex, amygdala, and endopiriform nucleus. Additional connections were found with various other structures, including olfactory areas, nucleus accumbens, midline thalamus, and brainstem nuclei including the substantia nigra and the dorsal raphe nucleus. The anatomical connections of the anterior claustrum are consistent with its very high susceptibility to kindling and support the view that the claustrum is part of a forebrain network of structures participating in the generalization of seizures.

Key words: kindling; epilepsy; seizure; claustrum; PHA-L; Fluoro-Gold; epileptogenesis

lesions can also damage fibers of passage. We recently observed that the posterior claustrum shares many characteristics of kindling with the perirhinal cortex (Mohapel et al., 1998, 1999), the region showing the fastest rate of kindling in the forebrain (McIntyre et al., 1993; Kelly and McIntyre 1996). Kindling from the posterior claustrum passes through two distinct phases. Early kindling involves extremely rapid progression to bilaterally generalized seizures with little partial seizure expression. With repeated daily stimulations, the short generalized seizures abruptly become more elaborate and prolonged, resembling limbic-type seizures triggered from the amygdala (Mohapel et al., 1998, 1999). The rapid rate of kindling from the posterior claustrum could be taken to suggest that it is functionally close to the mechanisms of seizure generalization.

Anatomical data indicate that the anterior claustrum has prominent connections with the motor and frontal cortex (Minciacchi et al., 1985; Sloniewski et al., 1986b; Sadowski et al., 1997a,b; Kowianski et al., 1998a,b), which play a pivotal role in kindling (Corcoran et al., 1976; Kelly et al., 1999). We therefore hypothesized that the anterior claustrum is also markedly susceptible to kindling. The present experiment was designed to test the hypothesis in rats.

Previous neuroanatomical studies on the claustrum have focused on neuronal connections between claustrum and neocortex, but no comprehensive investigation of the afferent and efferent connections of the claustrum is available. Such data could clarify the contribution of claustrum to epileptogenesis. We therefore also examined the connections of the anterior claustrum by use of iontophoretic delivery of the anterograde tract-tracing agent Phaseolus vulgaris leucoagglutinin (PHA-L) (Gerfen and 
Sawchenko, 1984) and the retrograde tract-tracing agent FluoroGold (FG) (Schmued and Fallon, 1986) into the anterior claustrum. The results reveal extensive afferent and efferent connections of the anterior claustrum with many forebrain structures reportedly involved in epilepsy.

\section{MATERIALS AND METHODS}

Animals. Adult male Long-Evans hooded rats, weighing 300-350 gm at the time of surgery, were used. The rats were housed under controlled temperature and light conditions ( $12 \mathrm{hr}$ light/dark cycle with lights on at 8:00 A.M.), with ad libitum access to food and water. All procedures were in strict accordance with the guidelines established by the Canadian Council on Animal Care as approved by the University of Saskatchewan Animal Care Committee.

Kindling. After $7 \mathrm{~d}$ of habituation to the colony, rats were anesthetized with sodium pentobarbital (Somnotol; $65 \mathrm{mg} / \mathrm{kg}$, i.p.) and placed in a stereotaxic instrument. Bipolar stimulating/recording electrodes constructed of twisted strands of nichrome wire, $127 \mu \mathrm{m}$ in diameter and insulated with enamel, were implanted bilaterally into the anterior claustrum. The stereotaxic coordinates were $2.8 \mathrm{~mm}$ anterior to bregma, 2.1 $\mathrm{mm}$ lateral to the midline, and $4.5 \mathrm{~mm}$ ventral to the surface of the brain, with the incisor bar set at $-3.8 \mathrm{~mm}$ (Paxinos and Watson, 1998). A reference wire and four additional dental screws were anchored to the skull, and then all the wires and screws were affixed to the skull with dental acrylic.

One week after surgery, afterdischarge (AD) thresholds were determined at one of the two electrodes. Electrical stimulation consisted of a $1 \mathrm{sec}$ train of balanced biphasic square-wave pulses of $1 \mathrm{msec}$ duration and delivered at $60 \mathrm{pps}$. Stimulation was delivered initially at $100 \mu \mathrm{A}$ (base to peak) and increased in increments of $100 \mu \mathrm{A}(<1000 \mu \mathrm{A})$ or $1000 \mu \mathrm{A}(>1000 \mu \mathrm{A})$ until AD was triggered (Pelletier and Corcoran, 1992, 1993). AD threshold (ADT) was arbitrarily defined as the lowest intensity to evoke an $\mathrm{AD}$ lasting $\geq 5 \mathrm{sec}$. One day later, claustrum kindling commenced, involving stimulation of the anterior claustrum once daily at ADT. The duration and intensity of AD and the behavioral seizures stages (Racine, 1972) were recorded after each stimulation. After kindling of stage 5 seizures and a concomitant $\mathrm{AD}$ lasting $>35 \mathrm{sec}$, the rats were killed by overdose with sodium pentobarbital $(100 \mathrm{mg} / \mathrm{kg}$, i.p.) and perfused through the heart with saline followed by $10 \%$ formaldehyde. Brains were removed from the skull, immersed in $30 \%$ sucrose for $2-10 \mathrm{~d}$ at $4^{\circ} \mathrm{C}$, and sectioned on a sliding microtome into $50-\mu \mathrm{m}$-thick sections. The sections were mounted on glass slides and stained with cresyl violet for routine examination of electrode locations.

FG and PHA-L ejections. Naive rats were anesthetized with sodium pentobarbital $(60 \mathrm{mg} / \mathrm{kg}$, i.p.) and placed in a stereotaxic instrument for iontophoretic ejection of FG into the anterior claustrum. Other rats received ejection of PHA-L into the anterior claustrum. FG (Fluorochem Inc., Denver, CO) was dissolved in filtered $(0.22 \mu \mathrm{m}) 0.1 \mathrm{M}$ sodium

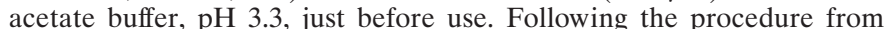
previous studies (Pieribone and Aston-Jones, 1988; Chen and Su, 1990), an iontophoretic ejection of a $1 \%$ solution of FG was made through a glass micropipette (tip diameter $10-20 \mu \mathrm{m}$ ) by applying a $+1.0 \mu \mathrm{A}$ current pulsed at $7 \mathrm{sec}$ intervals provided by a constant-current source (Stoelting, Wood Dale, IL), for $5 \mathrm{~min}$. A single iontophoretic ejection of a $2.5 \%$ solution of PHA-L (Vector Laboratories, Burlingame, CA) in 0.1 M sodium phosphate buffer, $\mathrm{pH} 7.4$, was made through a glass micropipette (tip diameter $15-25 \mu \mathrm{m}$ ) by applying a $+5.0 \mu \mathrm{A}$ current pulsed at $7 \mathrm{sec}$ intervals for $15-30 \mathrm{~min}$. The micropipette was withdrawn 5-10 min after ejection of PHA-L or FG. The coordinates for PHA-L and FG ejection were the same as those used for implantation of electrodes.

Ten days after FG and PHA-L ejection, each animal was deeply anesthetized with sodium pentobarbital $(100 \mathrm{mg} / \mathrm{kg}$, i.p.) and perfused transcardially with $150 \mathrm{ml}$ of $0.1 \mathrm{M} \mathrm{PBS}$, pH 7.4, followed by $250 \mathrm{ml}$ of freshly prepared $4 \%$ paraformaldehyde in PBS. The brains were immediately removed, post-fixed for $2 \mathrm{hr}$ in the same fixative, and immersed in $30 \%$ sucrose dissolved in PBS at $4^{\circ} \mathrm{C}$ for $2-3 \mathrm{~d}$.

FG and PHA-L immunohistochemistry. Frozen sections $40 \mu \mathrm{m}$ thick were prepared on a sliding microtome in the frontal plane and collected through the olfactory bulbs and forebrain to the midbrain and hindbrain. All sections were collected and divided into five series: two series of sections were stored at $4^{\circ} \mathrm{C}$ for later use; one series of sections was stained for cresyl violet to facilitate the identification of specific brain nuclei; and the adjacent two series of sections were processed for FG and PHA-L immunohistochemical staining using a conventional avidin-bi- otin-immunoperoxidase technique as described previously in detail (Zhang et al., 1996, 1997a,b). Briefly, this procedure included pretreating sections at room temperature for $30 \mathrm{~min}$ in $0.2 \%$ hydrogen peroxide and for $1 \mathrm{hr}$ in the blocking buffer containing PBS, $0.3 \%$ Triton $\mathrm{X}-100$, and $5 \%$ normal goat serum (for FG stain) or 5\% normal rabbit serum (for PHA-L stain). Sections were then incubated in the primary rabbit anti-FG antibody (1:5000; Chemicon, Temecula, CA) or the goat antiPHA-L antibody (1:2000; Vector Laboratories, Burlingame, CA) diluted in the blocking buffer at $4^{\circ} \mathrm{C}$ for $3 \mathrm{~d}$ on a shaker. The primary antibodies were localized using Vectastain Elite reagents (Vector Laboratories); namely, sections were incubated sequentially in biotinylated anti-rabbit or anti-goat $\operatorname{IgG}(1: 250)$ and avidin-biotinylated horseradish peroxidase complex (1:100) for $2 \mathrm{hr}$ at each incubation. The reaction product was developed by incubating the sections in a solution containing diaminobenzidine and hydrogen peroxide at room temperature for 5-10 min. The sections were mounted on slides, which were then air dried, dehydrated, cleared, and coverslipped with DPX.

Data analysis. The measures of kindling included the following: ADT; $\mathrm{AD}$ duration; the latency to the first bilateral forelimb clonus; the duration of forelimb clonus; the rate of kindling, which was defined as the number of daily stimulations necessary to trigger the first stage 5 motor seizure according to Racine's scale (Racine, 1972) as well as to trigger the first stage 5 motor seizure with an AD exceeding $30 \mathrm{sec}$; and AD duration over the first two stage 5 seizures. Statistical analysis of the data was performed using a one-way ANOVA, and post hoc comparisons were performed with $t$ tests.

Sections stained with FG or PHA-L immunohistochemistry were examined with a Zeiss microscope with both bright-field and dark-field illumination. The distribution of FG- and PHA-L-labeled neuronal component in the ejection sites was plotted onto maps prepared from adjacent Nissl-stained sections. Illustrations were prepared by charting the distribution of retrogradely labeled cells (in the case of FG ejection) or anterogradely labeled fibers (in the case of PHA-L ejection) onto a series of standard drawings of the rat brain. In transposing our results onto standard drawings, we carefully compared the cytoarchitectonic features of adjacent Nissl-stained sections to ensure an accurate match between the actual experimental section being mapped and the corresponding standard section illustrated in the reference atlas (Paxinos and Watson, 1998). Ejection sites and axon and neuronal distributions were photographed, the films were scanned with a high resolution (2700 dpi) film scanner (Nikon, Super Coolscan 2000), and the images were digitally processed with Adobe Photoshop 5.0. Each image was adjusted for optimal contrast and morphological clarity. Layout was accomplished by using both Adobe Photoshop 5.0 and Adobe Illustrator 8.0. Each gray scale figure was then printed out with an HP PhotoSmart P1100 printer with a color cartridge, which produces high-quality photomicrographs (up to $2400 \times 1200$ dpi in resolution).

\section{RESULTS \\ Nomenclature}

Some researchers (LeVay and Sherk, 1981; Morys and Sloniewski, 1986; Sherk, 1988; Dinopoulos et al., 1992; Sadowski et al., 1997a,b) have argued that the claustrum consists of two parts, the insular (or dorsal) claustrum, which underlies the insular cortex, and the prepiriform (or piriform or ventral) claustrum, which is also referred to as the endopiriform or dorsal endopiriform nucleus. In the present study, however, we favor the concept first established by Krettek and Price (1977a) that the terms claustrum and dorsal endopiriform nucleus are reserved for the "insular claustrum" and the "prepiriform claustrum," respectively, for the following reasons. First, it has long been shown that the claustrum is a cortically related structure originating from the cortex (Meynert, 1868; Brodmann, 1909; de Vries, 1910; Macchi, 1951; Filiminoff, 1966; Bayer and Altman, 1991; Bayer et al., 1993), whereas the dorsal endopiriform nucleus is generated in the palliostriatal ventricular angle (Bayer and Altman, 1991; Bayer et al., 1993). Second, the claustrum is heavily and reciprocally connected with neocortex (Druga, 1972, 1982; Carey and Neal, 1985; Minciacchi et al., 1985; Morys and Sloniewski, 1986; Sloniewski et al., 1986b; Druga et al., 1990; Clasca et al., 1992; 
Dinopoulos et al., 1992; Kowianski et al., 1996, 1998a; Sadowski et al., 1997a,b), whereas the dorsal endopiriform nucleus is mainly connected with the piriform, entorhinal, insular, and orbital cortices (Krettek and Price, 1977a,b, 1878a,b; Haberly and Price, 1978; Markowitsch et al., 1984; Wilhite et al., 1986; Witter et al., 1988; Behan and Haberly, 1999).

The claustrum borders the orbital cortex anteriorly, the perirhinal cortex caudally, and the entire extent of the insular cortex laterally. The ventral border of the claustrum lies sequentially with the orbital cortex, which is ventral to the anterior claustrum, and the dorsal endopiriform nucleus, which is ventral to the middle and posterior parts of the claustrum (the rhinal fissure divides the middle and posterior parts of the claustrum from the dorsal endopiriform nucleus). Medial to the anterior claustrum is the forceps minor corpus callosum, whereas medial to the middle and posterior claustrum lies the external capsule (which is itself medial to the caudate-putamen). The forceps minor corpus callosum and the somatosensory cortex overlie, respectively, the anterior and the remaining parts of the claustrum. The term "anterior claustrum" as used throughout this paper is similar to the claustrum presented in Paxinos and Watson (1998, their Figs. 7-9) and in Swanson (1998, his Plates 7-9), whereas the term "posterior claustrum" as used here is similar to the claustrum appearing in Paxinos and Watson (1998, their Figs. 25-27) and in Swanson (1998, his Plates 25-27). Percolation of each structure or region and the associated nomenclature used in the present study were derived primarily from the atlas of the rat brain provided by Paxinos and Watson (1998).

\section{Anterior claustrum kindling}

Kindling data were obtained from seven rats with accurate electrode placements in the anterior claustrum (Fig. 1A,B). For comparison, kindling from stimulation of the basolateral nucleus of the amygdala was examined in 11 additional rats. Kindling from the anterior claustrum progressed through two distinct phases of generalized seizure development, similar to the pattern of kindling from stimulation of the posterior claustrum (Mohapel et al., 1998, 1999). The early stage 5 seizure phase involved very rapid progression to generalized seizure stages 4 and 5, with little or no partial seizure expression. On repeated daily stimulations, these short generalized stage 5 seizures abruptly became more elaborate and prolonged (late phase). To fully describe anterior claustrum kindling and compare it with amygdaloid kindling, we compared kindling from the two sites in terms of characteristics of $\mathrm{AD}$, features of behavioral seizures, and speed of kindling.

\section{Characteristics of $A D$}

The mean $( \pm$ SEM) AD threshold in the anterior claustrum was much higher than in the amygdala $(471.43 \pm 94.40 \mu \mathrm{A}$ vs $50.91 \pm$ $4.56 \mu \mathrm{A}$, respectively; $t_{(17)}=5.669 ; p<0.01$ ), as shown in Table 1. The mean duration of the initial $\mathrm{AD}$ in the anterior claustrum was significantly longer than in the amygdala $(12.71 \pm 2.35 \mathrm{sec}$ vs $5.64 \pm 0.90 \mathrm{sec}$, respectively; $t_{(17)}=3.677 ; p<0.01$ ) (Table 1 ), and repeated-measures ANOVA indicated that there was a significant difference in the change in AD durations between groups $\left(F_{(16,1)}=5.94 ; p<0.01\right)$ and over time $\left(F_{(16,2.811)}=9.83 ; p<\right.$ $0.05)$, with a significant interaction $\left(F_{(16,2.811)}=2.95 ; p<0.05\right)$.

\section{Speed of kindling}

Repeated-measures ANOVA indicated that kindling to different seizure stages differed between the groups $\left(F_{(16,1)}=22.83 ; p<\right.$ $0.01)$ and over time $\left(F_{(16,7)}=29.45 ; p<0.01\right)$, with a significant interaction $\left(F_{(16,7)}=6.23 ; p<0.01\right)$. Stimulation of the anterior claustrum required significantly fewer ADs to kindle the first bilateral clonus $\left(t_{(17)}=-5.310 ; p<0.01\right)$ and the first stage 5 seizure $\left(t_{(17)}=-2.649 ; p<0.05\right)$ than did the amygdala, as shown in Table 2 and Figure $2 A$. The first stimulation of the anterior claustrum at ADT provoked stage 2 or 3 seizures. Bilateral clonus developed after a mean of 3.0 claustrum ADs, significantly faster than the 8.1 ADs with amygdaloid stimulation, and the first stage 5 seizure developed after 5.6 claustrum ADs, significantly faster than the 9.4 ADs with amygdaloid stimulation (Table 2). This corresponds to the early phase of kindling we have observed previously with stimulation of the posterior claustrum (Mohapel et al., 1998, 1999).

To characterize the transition into the late phase of limbic-type stage 5 seizures, we noted the first AD on which rats exhibited a stage 5 seizure that exceeded $30 \mathrm{sec}$ in AD duration. As reported previously (Mohapel et al., 1998, 1999), this measurement corresponds closely to a twofold increase in $\mathrm{AD}$ duration from the immediately preceding stage 5 seizure, an additional criterion for limbic-type generalization. As shown in Table 2, the late phase of limbic-type generalized stage 5 seizures developed after a mean of 11.3 claustrum ADs, not significantly different from the 9.4 ADs required with amygdaloid stimulation $(p>0.05)$. We also measured the AD durations of the first early and late stage 5 seizures. Again, the mean AD duration in the first stage 5 seizures was significantly shorter in the anterior claustrum group than in the amygdaloid group $(p<0.05)$ (Table 1, Fig. 2B), whereas the first late-phase stage 5 seizure in the claustrum group did not differ significantly in duration from the first stage amygdaloid seizure (means of $40.5 \pm 10.1$ and $61.4 \pm 3.2 \mathrm{sec}$, respectively; $\left.t_{(9.5)}=1.972 ; p=0.078\right)$.

\section{Features of behavioral seizures}

The mean latency to bilateral forelimb clonus with stimulation of the anterior claustrum was much shorter than that with stimulation of the amygdala (Table 1$)\left(t_{(17)}=-1.999 ; p<0.01\right)$. Furthermore, the mean duration of bilateral forelimb clonus in early stage 4 or stage 5 claustrum seizures was significantly shorter than in generalized amygdaloid seizures $\left(t_{(17)}=7.104\right.$, $p<0.0001$ for stage $4 ; t_{(17)}=-5.309, p<0.0001$ for stage 5$)$, whereas the difference in duration of the first late stage 5 claustrum seizure from stage 5 amygdaloid seizures was not statistically significant (Table 2).

Figure $1 C$ shows a typical EEG profile recorded from the anterior claustrum in a rat exhibiting late-phase stage 5 seizures. Stimulation triggered short cortical-like AD, during which brief stage 3 or 4 seizures occurred. The AD and behavioral seizure were immediately followed by the appearance of a limbic-like stage 5 behavioral seizure and AD. After amygdaloid stimulation, however, rats showed the typical gradual onset of AD, culminating in the development of sequential behavioral seizures of stages 2, 3, 4, and 5 (Fig. 1D).

\section{Efferent connections of the anterior claustrum}

PHA-L ejection sites with varying numbers of clearly labeled neurons in the anterior claustrum and surrounding region were obtained in nine animals. Of these, three deposits were restricted within the morphological limits of the anterior claustrum (Fig. $3 A$ ), three were in the core area of the anterior caudate putamen posterior to the anterior claustrum, two were in the ventral orbital cortex ventral to the anterior claustrum, and one was in the lateral orbital cortex ventrolateral to the anterior claustrum. The distri- 


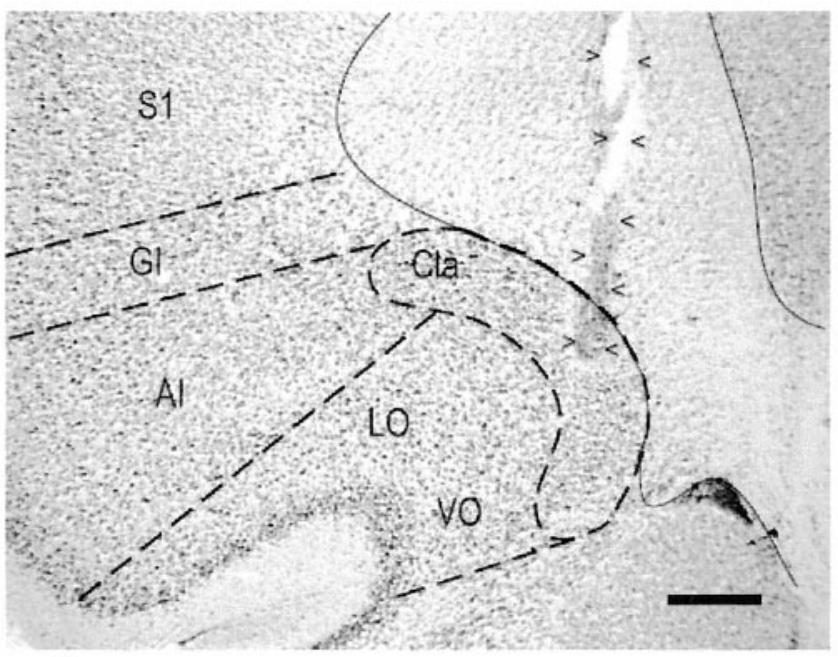

A

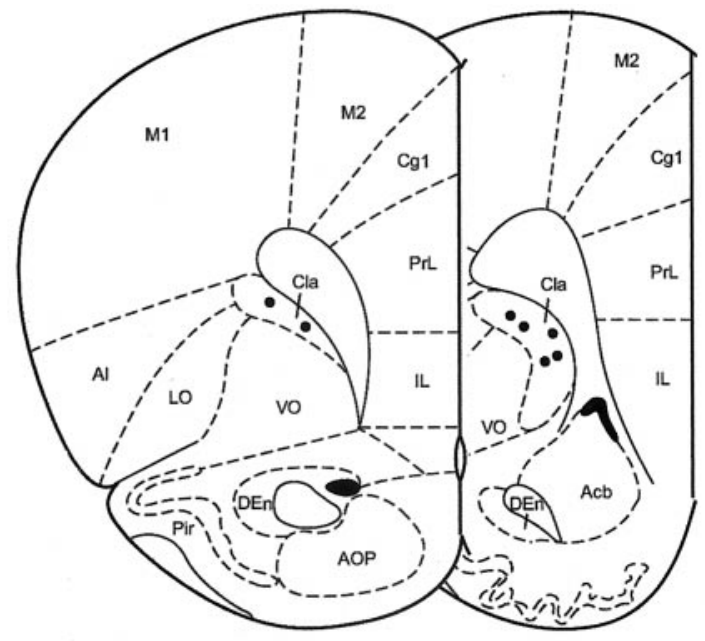

Bregma $3.2 \mathrm{~mm} \quad$ Bregma $2.7 \mathrm{~mm}$
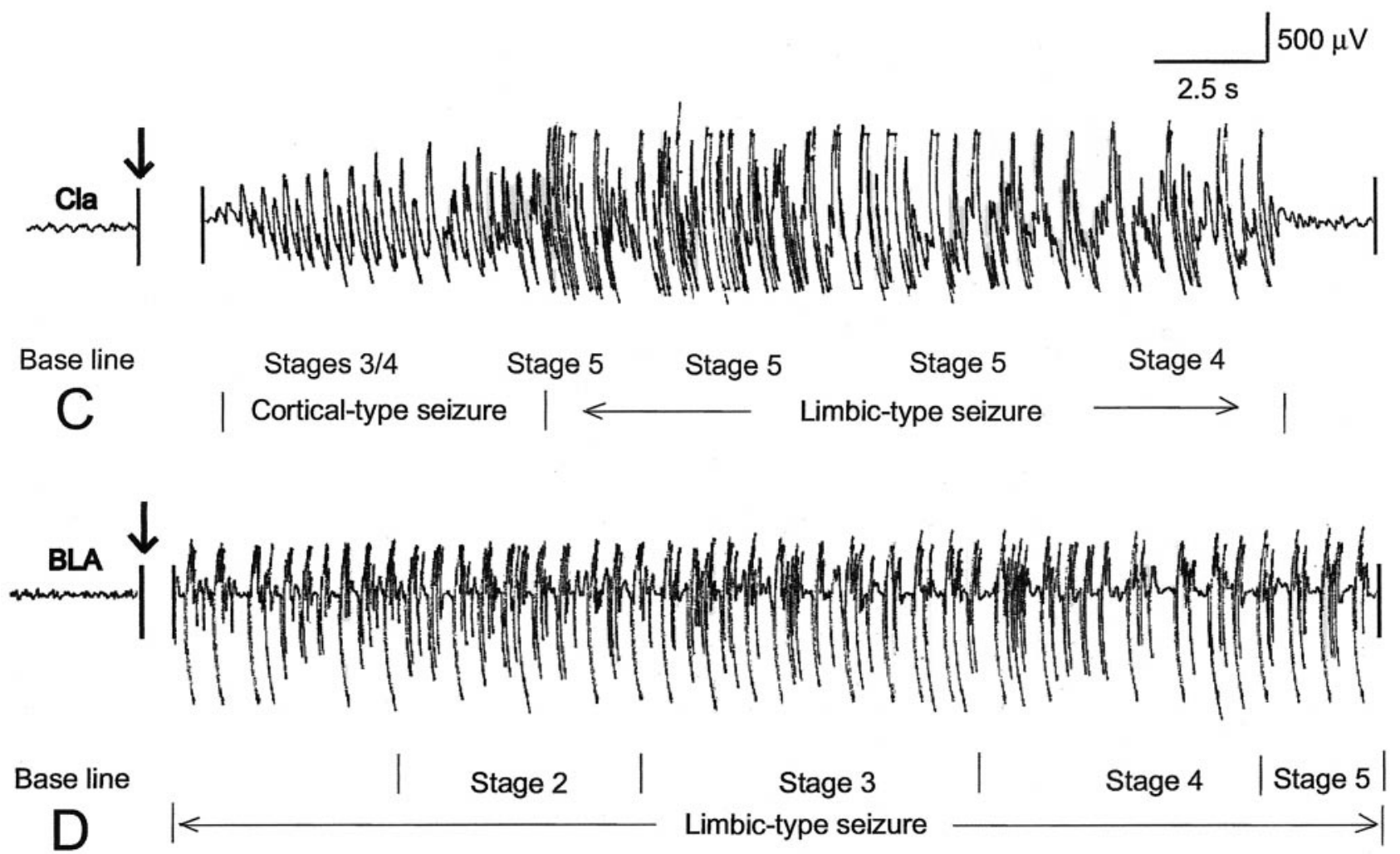

Figure 1. Kindling site and EEG pattern. A, Bright-field microphotograph showing the location of an implanted electrode. Arrowheads indicate the track of the electrode, with the electrode tip located within the anterior claustrum. B, Schematic representation of the location of electrode tips (black dots) in the anterior claustrum in the seven rats that received kindling stimulation. $C$, A typical EEG profile associated with a seizure kindled from the anterior claustrum. After electrical stimulation the rat almost immediately exhibited stages $3 / 4$ seizures, several episodes of stage 5 seizures, and one episode of stage 4 seizures in sequence, which were accompanied by a relatively short period of cortical-type EEG seizure and a relatively long-lasting limbic-type seizure. $D$, A typical EEG profile of a seizure kindled from the basolateral amygdaloid nucleus. After stimulation the rat showed a limbic-type EEG seizure lasting for $2 \mathrm{~min}$, whereas no obvious behavioral seizure appeared until $10 \mathrm{sec}$ after stimulation, at which time the rat began to sequentially show stages 2, 3, 4, and 5 seizures. $A c b$, Accumbens nucleus; $A I$, agranular insular cortex; $A O P$, anterior olfactory nucleus, posterior part; $C g 1$, cingulate cortex, area 1; Cla, claustrum; $D E n$, dorsal endopiriform nucleus; $G I$, granular insular cortex; $I L$, infralimbic cortex; $L O$, lateral orbital cortex; $M 1$, primary motor cortex; M2, secondary motor cortex; Pir, piriform cortex; PrL, prelimbic cortex; S1, primary somatosensory cortex; $V O$, ventral orbital cortex. Also see Results for a more complete account of the contralateral afferent connections. Scale bar, $520 \mu \mathrm{m}$.

bution of anterior claustrum projections is schematically illustrated in Figure 4, which is based primarily on the results in rat 99217 (Fig. 3). The pattern of distribution was quite similar to those in two other rats with PHA-L deposits centered in the anterior claustrum, but differed greatly from the pattern in rats with PHA-L ejection outside the claustrum.

Axonal labeling at the rostral cerebral cortex appeared in all regions of the prefrontal cortex, the nomenclature for which is 


\begin{tabular}{|c|c|c|c|c|}
\hline Kindling site & $\begin{array}{l}\text { Initial ADT } \\
(\mu \mathrm{A})\end{array}$ & $\begin{array}{l}\text { Initial AD } \\
\text { duration (sec) }\end{array}$ & $\begin{array}{l}\text { AD duration at first } \\
\text { early stage } 5 \text { seizure }\end{array}$ & $\begin{array}{l}\text { AD duration at first } \\
\text { late stage } 5 \text { seizure }\end{array}$ \\
\hline Anterior CLA & $471.4 \pm 94.4^{* *}$ & $12.7 \pm 2.4^{* *}$ & $20.5 \pm 2.1^{* *}$ & $50.4 \pm 10.3$ \\
\hline Amygdala & $50.9 \pm 4.6$ & $5.6 \pm 0.9$ & $60.5 \pm 8.2$ & $68.3 \pm 8.3$ \\
\hline
\end{tabular}

Data are depicted as means \pm SEMs.

$* * p<0.001$.

Table 2. Speed of kindling and features of behavioral seizures with kindling of anterior claustrum (CLA) and amygdala

\begin{tabular}{|c|c|c|c|c|c|c|c|}
\hline Kindling site & $\begin{array}{l}\text { Number of ADs } \\
\text { to first bilateral } \\
\text { clonus }\end{array}$ & $\begin{array}{l}\text { Number of ADs } \\
\text { to first early } \\
\text { stage } 5 \text { seizure }\end{array}$ & $\begin{array}{l}\text { Latency to clonus } \\
(\mathrm{sec}) \text { in first early } \\
\text { stage } 5 \text { seizure }\end{array}$ & $\begin{array}{l}\text { Duration }(\mathrm{sec}) \\
\text { of first early } \\
\text { stage } 5 \text { seizure }\end{array}$ & $\begin{array}{l}\text { Number of ADs } \\
\text { to first late } \\
\text { stage } 5 \text { seizure }\end{array}$ & $\begin{array}{l}\text { Latency to clonus } \\
\text { of first late stage } \\
5 \text { seizure }\end{array}$ & $\begin{array}{l}\text { Duration of } \\
\text { first late stage } \\
5 \text { seizure }\end{array}$ \\
\hline Anterior CLA & $3.0 \pm 0.6^{* *}$ & $5.6 \pm 1.4^{*}$ & $1.7 \pm 0.4^{*}$ & $18.1 \pm 1.9^{* *}$ & $9.3 \pm 1.3$ & $1.0 \pm 0.7^{*}$ & $40.5 \pm 10.1$ \\
\hline Amygdala & $8.1 \pm 0.7$ & $9.4 \pm 0.7$ & $11.7 \pm 4.2$ & $54.0 \pm 4.0$ & $9.2 \pm 0.8$ & $9.6 \pm 3.5$ & $61.4 \pm 3.2$ \\
\hline
\end{tabular}

Data are depicted as means \pm SEMs.

${ }^{*} p<0.05 ;{ }^{*} p<0.001$.
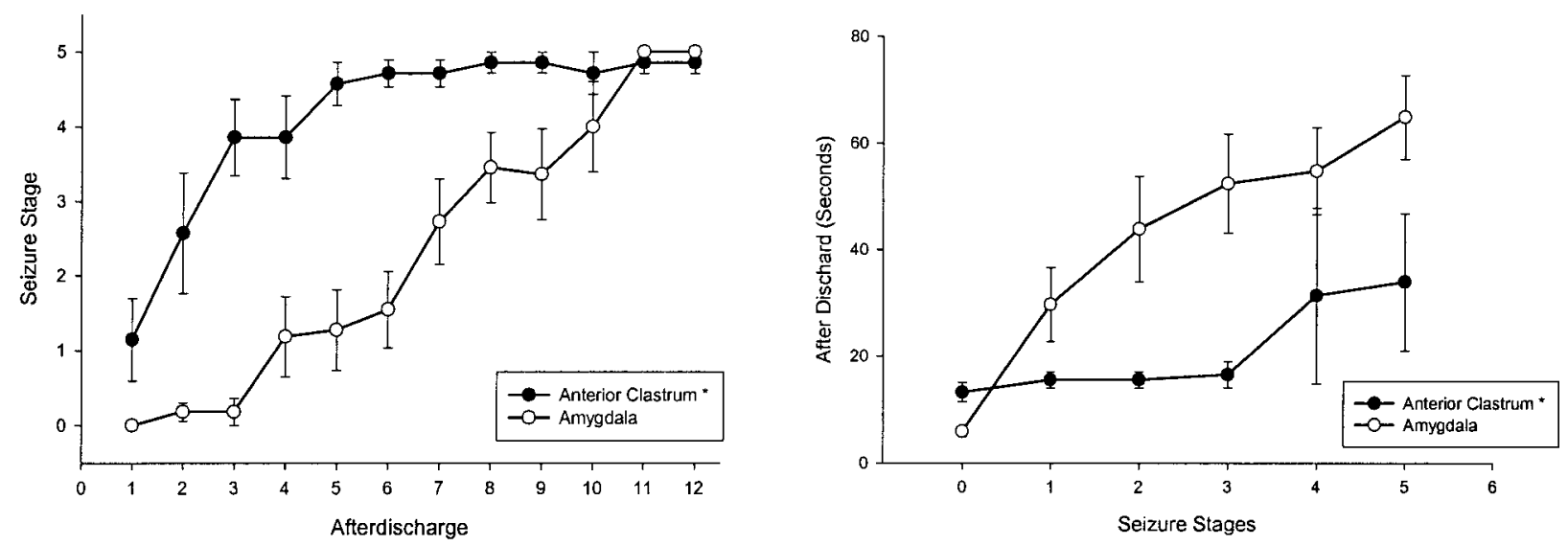

Figure 2. Kindling profiles in the anterior claustrum and basolateral amygdaloid nucleus. $A$, Behavioral seizure stages plotted against the corresponding afterdischarges. $B$, Duration of afterdischarges plotted against motor seizures.

based on a combination of classical (Kolb, 1990) and recent (Paxinos and Watson, 1998) descriptions of this region. The prefrontal cortex consists of the secondary motor cortex (equivalent to area 2 of the frontal cortex), area 1 of the anterior cingulate cortex, prelimbic cortex (equivalent to area 3 of the cingulate cortex), and infralimbic, orbital, and anterior insular cortices. Numerous labeled axons with dense varicosities ran in the secondary motor cortex and area 1 of the anterior cingulate cortex from layer VI up into layer III, and many labeled axons continued to head into the superficial layers. Ventral or anterior to the anterior cingulate cortex, axonal labeling decreased significantly in both the prelimbic and infralimbic cortices, where a low density of labeled fibers with a moderate density of varicosities was seen upward and inward in all the layers. A similar density of PHA-L labeling was also observed in the medial and dorsolateral orbital cortices. Although layers II and III of the lateral and ventral orbital cortices displayed a high density of fine axons with numerous varicosities, deep layers contained low to moderate densities of labeled fibers (Fig. 3B). The ipsilateral secondary motor cortex, area 1 of the anterior cingulate cortex, and lateral and ventral orbital cortices were innervated significantly more than the contralateral side. The anterior insular cortex, which consists of granular and agranular parts, was occupied by a few labeled axons scattered over deep layers. These results confirm the findings of previous retrograde tracing studies showing that the claustrum innervates the prefrontal parts of the secondary motor cortex and area 1 of the cingulate cortex, and ventral and lateral orbital cortices heavily on the ipsilateral side and much less heavily on the contralateral side (Divac et al., 1978; Donoghue and Parham, 1983; Conde et al., 1995; Reep et al., 1996), and that the prelimbic, infralimbic, and medial orbital cortices receive a direct innervation from a few neurons in the ipsilateral anterior claustrum (Conde et al., 1995; Reep et al., 1996).

In addition to the prefrontal cortex, other cortical areas also exhibited varying degrees of PHA-L labeling. Thus the dorsomedial area of the frontal association cortex, a region just anterior to the secondary motor cortex, showed numerous labeled axons, whereas other parts of the frontal association cortex showed very low to low densities of labeled fibers. The number of labeled fibers decreased obviously from the anterior cingulate cortex to the middle and posterior cingulate cortices, which showed a low concentration of fine axons. Farther caudal to the cingulate cortex, the agranular retrosplenial cortex also contained a low concentration of fine axons located in layers II-VI, whereas only a few labeled axons were detected in the granular retrosplenial cortex. These projections from claustrum to retrosplenial cortex 

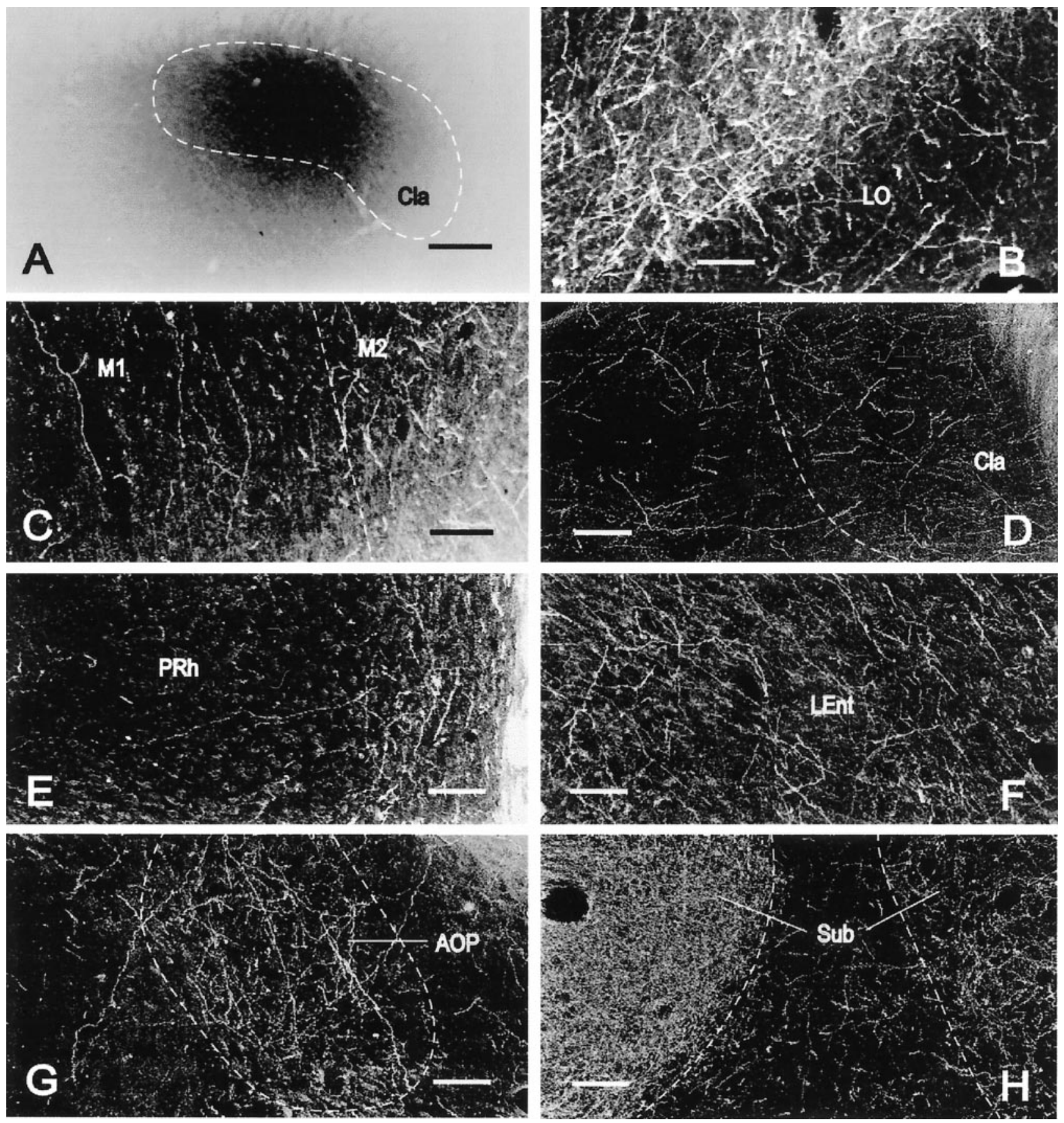

Figure 3. Localization of PHA-L immunoreactivity in the rat brain. Bright-field $(A)$ and dark-field $(B-H)$ microphotographs of coronal sections showing an ejection site and the distribution of PHA-L-immunoreactive axons in representative brain regions in rat 99217. $A$, PHA-L occupied the major part of the anterior claustrum with minimal spread outside the morphological limits of the anterior claustrum. $B$, Layer II of the lateral orbital cortex was occupied with a high density of labeled fibers, whereas layer I exhibited low to moderate density of labeled axons. $C$, In contrast with the primary motor cortex (on the left side of the image), with a low concentration of labeled fibers oriented perpendicularly to the cortical surface, many axons with a moderate density of varicosities were distributed with no specific direction in the secondary motor cortex (on the right side of the image). $D$, The middle part of the claustrum exhibited many fine, labeled axons, some of which ran laterally into the adjacent insular cortex toward the cortical surface. $E$, Although many fibers oriented parallel to the cortical surface in deep layers of the perirhinal cortex (on the right side of the image), some axons were oriented perpendicularly to the cortical surface in the superficial layers of the perirhinal cortex (on the left side of the image). $F$, Numerous axons with many varicosities ran dorsoventrally in deep layers of the posterior part of the lateral entorhinal cortex. $G$, Many labeled fibers were concentrated within the morphological limits of the posterior part of the anterior olfactory nucleus. $H$, The submedius thalamic nucleus ipsilateral to the ejection site (on the left side of the image) was fully occupied by an especially high density of numerous terminal-like axons, whereas the contralateral submedius thalamic nucleus (on the right side of the image) contained a much lower concentration of terminal-like axons. LEnt, Lateral entorhinal cortex; PRh, perirhinal cortex; Sub, submedius thalamic nucleus. All other abbreviations are as indicated in Figure 1. Scale bars: $A, 290 \mu \mathrm{m} ; B-H, 110 \mu \mathrm{m}$. 

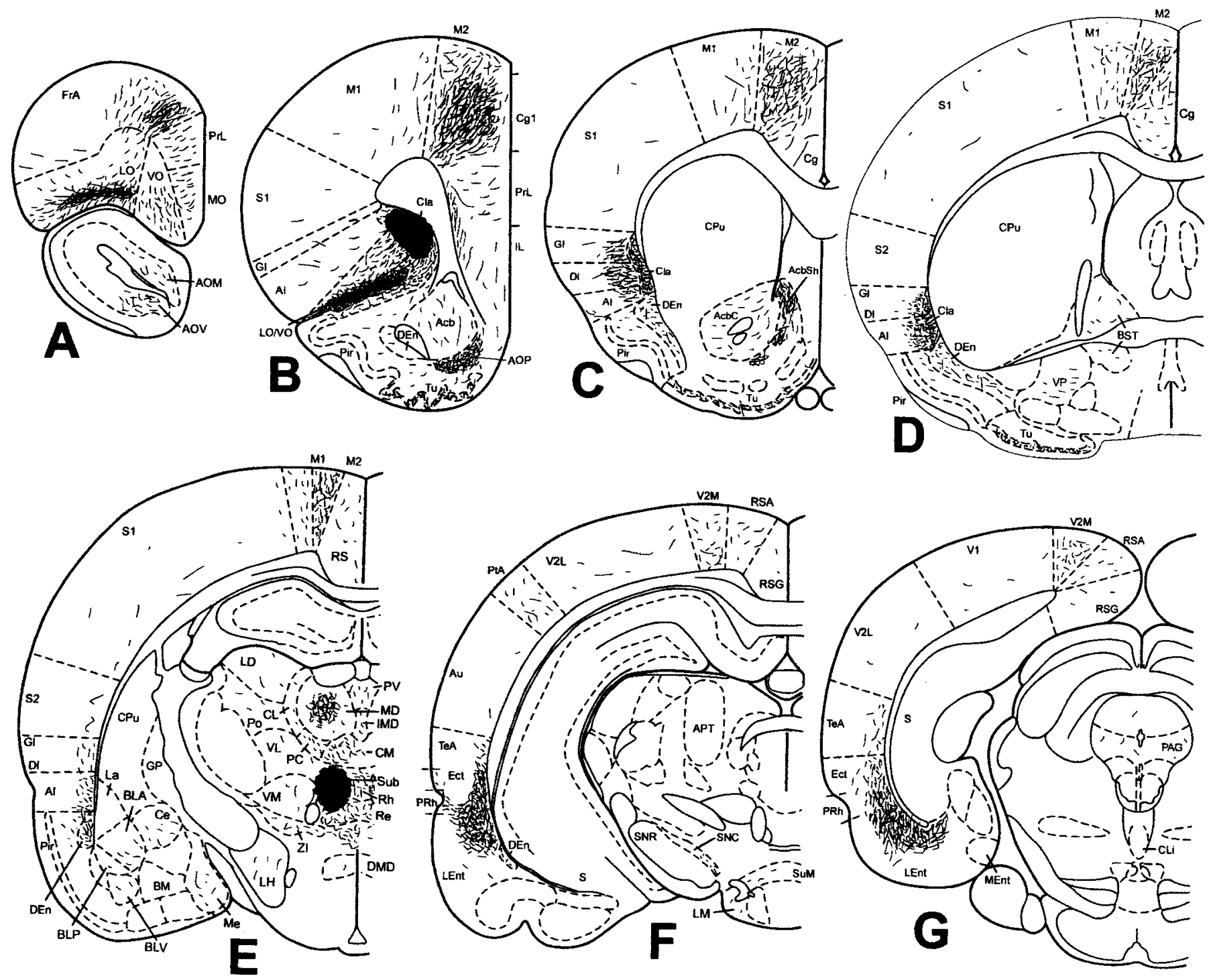

Figure 4. Projections of the anterior claustrum in rat 99217. Schematic representation of the density and localization of PHA-L-labeled fibers determined by immunohistochemistry was plotted from seven representative coronal sections corresponding to bregma $4.70,2.70,1.20,-0.26,-2.56$, -4.80 , and $-6.80 \mathrm{~mm}(A-G$, respectively). The irregular dark area in $B$ indicates the ejection site, which is illustrated in Figure $3 A$. The full extent of labeled axons contralateral to the injection is not shown (see Results for more complete account of the contralateral projection). This schematic was generated on an IBM-compatible computer using Paxinos and Watson (1998). AcbC, Accumbens nucleus, core; $A c b S h$, accumbens nucleus, shell; $A O M$, anterior olfactory nucleus, medial part; $A O V$, anterior olfactory nucleus, ventral part; $A P T$, anterior pretectal nucleus; $A u$, secondary auditory cortex; $B L A$, basolateral amygdaloid nucleus, anterior part; $B L P$, basolateral amygdaloid nucleus, posterior part; $B L V$, basolateral amygdaloid nucleus, ventral part; $B M$, basomedial amygdaloid nucleus; $B S T$, bed nucleus of the stria terminalis; $C e$, central amygdaloid nucleus; $C g$, cingulate cortex; $C L$, centrolateral thalamic nucleus; $C l i$, caudal linear nucleus of the raphe; $C M$, central medial thalamic nucleus; $C P u$, caudate putamen; $D I$, dysgranular insular cortex; $D M D$, dorsomedial hypothalamic nucleus, dorsal part; Ect, ectorhinal cortex; FrA, frontal association cortex; GP, globus pallidus; IMD, intermediodorsal thalamic nucleus; $L a$, lateral amygdaloid nucleus; $L D$, laterodorsal thalamic nucleus; $L H$, lateral hypothalamic area; $L M$, lateral mammillary nucleus; $M D$, mediodorsal thalamic nucleus; $M e$, medial amygdaloid nucleus; Ment, medial entorhinal cortex; $M O$, medial orbital cortex; $P A G$, periaqueductal gray; $P C$, paracentral thalamic nucleus; Po, posterior thalamic nuclear group; PtA, parietal association cortex; $P V$, paraventricular thalamic nucleus; Re, reuniens thalamic nucleus; $R h$, rhomboid thalamic nucleus; $R S$, retrosplenial cortex; $R S A$, retrosplenial agranular cortex; $R S G$, retrosplenial granular cortex; $S$, subiculum; $S 2$, secondary somatosensory cortex; $S N C$, substantia nigra, pars compacta; $S N R$, substantia nigra, pars reticulata; $S u M$, supramammillary nucleus; $T e A$, temporal association cortex; $T u$, olfactory tubercle; $V 1$, primary visual cortex; $V 2 L$, secondary visual cortex, lateral part; $V 2 M$, secondary visual cortex, medial part; $V L$, ventrolateral thalamic nucleus; $V M$, ventromedial thalamic nucleus; $V P$, ventral pallidum; $Z I$, zona incerta. All other abbreviations are as indicated in previous figures.

are in agreement with the recent findings obtained with retrograde tract-tracing techniques (van Groen and Wyss, 1990a, 1992a).

Similar to the cingulate cortex, the relative numbers of labeled fibers with numerous varicosities also decreased from a high density in the anterior part of the secondary motor cortex to the moderate density in the middle and posterior parts (Fig. 3C).
Although a few axons were observed in the primary motor cortex, which is equivalent to area 1 of the frontal cortex and located lateral to the secondary motor cortex, labeled fibers in both the primary and secondary motor cortices were similarly distributed in layers II-VI. A few labeled axons were detected in the rostrocaudal extent of the primary and secondary somatosensory cortices (equivalent to areas 1 and 2 of the parietal cortex), the 
lateral area of the secondary visual cortex, the primary visual cortex, and the auditory cortex. The parietal association cortex, the medial area of the secondary visual cortex, and deep layers of the temporal association cortex contained low to moderate densities of labeled axons distributed throughout layers II-VI. These findings confirm the recent observations with retrograde tracttracing techniques that both the medial area of the secondary visual cortex and the temporal association cortex receive direct projection from many neurons in the anterior claustrum (Sloniewski and Pilgrim, 1984; Carey and Neal, 1985; Burwell and Amaral, 1998).

Moderate to high densities of labeled axons run mediolaterally from the middle and posterior parts of the claustrum into deep layers of the granular and agranular insular cortex (Fig. 3D), and the superficial layers of the insular cortex were occupied with few, if any, labeled axons. Ventral to the claustrum, the dorsal endopiriform nucleus was moderately labeled, whereas a few fine axons were seen in the deep layers of the dorsal area of the piriform cortex. A strip of densely packed axons with numerous varicosities ran from the deep layers of the ectorhinal cortex, through the deep layers of the perirhinal cortex (Fig. 3E), and down into the deep layers of the lateral entorhinal cortex (Fig. $3 F$ ). Some fibers with varicosities running through deep layers emitted collaterals and then headed to superficial layers, a phenomenon especially evident in the perirhinal cortex. These results are consistent with a recent retrograde tract-tracing study showing that many neurons in the rat anterior claustrum innervate the ectorhinal, perirhinal, and lateral area of the lateral entorhinal cortex (Deacon et al., 1983; Burwell and Amaral, 1998). The medial entorhinal cortex as defined by Paxinos and Watson (1998) contained no PHA-L-labeled fibers (Fig. 4G).

Labeled fibers were distributed exclusively on the ipsilateral side in the major cortical areas mentioned above, with the exception of a light labeling that was detected in those cortical areas that showed high density of labeled axons, including the anterior part of the secondary motor cortex, superficial layers of the lateral and ventral orbital cortex, claustrum, perirhinal cortex, and lateral entorhinal cortex. These findings are generally consistent with recent studies (Minciacchi et al., 1985; Sloniewski et al., 1986b).

PHA-L labeling was also observed in various subcortical structures. Although a low density of labeled fibers was observed in the medial and ventral parts of the anterior olfactory nucleus, a high density of labeled axons was present in the posterior part (Fig. $3 G)$. Ventral and caudal to the anterior olfactory nucleus, the olfactory tubercle exhibited low to moderate densities of labeled fibers. Numerous labeled axons coursed ventrally in the shell of the nucleus accumbens, in contrast to the relative absence of fibers in the core of the accumbens. Caudal to the accumbens, the major parts of the bed nuclei of the stria terminalis and ventral pallidum were modestly labeled. Farther caudally, a modest density of labeled axons was also distributed in the nucleus of the lateral olfactory tract as well as in several amygdaloid nuclei, including the central nucleus, the anterior, posterior, and ventral parts of the basolateral nucleus, and the lateral nucleus.

In addition to the cerebral cortex as described above, another principal target of labeled fibers in the rat brain after PHA-L ejection into the anterior claustrum was the midline thalamus. The ipsilateral submedius nucleus was especially heavily labeled with significant terminal-like axons, whereas the contralateral submedius nucleus was moderately labeled (Fig. 3H). Dorsally, the central part of the mediodorsal nucleus was also moderately labeled unilaterally. Labeling was light to moderate in other midline thalamic nuclei, including the paraventricular, paracentral, central medial, intermediodorsal, interanteromedial, rhomboid, reuniens, and subparafascicular nuclei. Laterally, labeling was further modest in the centrolateral, laterodorsal, ventrolateral, ventromedial, and parafascicular nuclei, as well as in the posterior thalamic nuclear group and zona incerta. These results are generally consistent with previous findings of direct projections from the anterior claustrum to both the submedius thalamic nucleus (Yoshida et al., 1992) and many other thalamic nuclei (Groenewegen, 1988; Chen and Su, 1990).

The hypothalamus was also modestly labeled in the lateral and posterior hypothalamic areas, dorsal part of the dorsomedial nucleus, supramammillary nucleus, and lateral mammillary nucleus. Relatively light labeling was found in several structures in the ipsilateral brain stem, including the medial part of the substantia nigra, medial areas of both the reticular and compact parts of the substantia nigra, dorsolateral and lateral areas of the periaqueductal gray, and dorsal raphe nucleus.

\section{Afferent connections of the anterior claustrum}

Discrete FG ejection sites in the anterior claustrum and surrounding regions were obtained in 10 rats. Of these, four small ejections were contained completely within the territory of the anterior claustrum (Fig. 5A). As shown in Figure 6, which schematically illustrates the distribution of afferents to the anterior claustrum based primarily on the results obtained in rat 99143 (Fig. 5), four major structures exhibited marked concentrations of retrogradely labeled neurons after a unilateral FG ejection into the anterior claustrum: the cerebral cortex, amygdaloid complex, thalamus, and several brainstem nuclei.

Two strips of low to moderate densities of FG-labeled neurons concentrated in layers II and V were seen in the medial prefrontal cortex, including the secondary motor cortex, area 1 of the anterior cingulate cortex, and prelimbic cortex. The orbital cortex contained varying degrees of labeled cells, with moderate to high densities in layers II-IV in the medial and ventral orbital cortices (Fig. $5 B$ ), and a low density in deep layers of the medial and ventral orbital cortices as well as in the lateral orbital cortex. Labeled cells in the prefrontal regions were distributed bilaterally, with a higher density ipsilaterally. In addition, a few labeled cells were also detected in the deep layers of the dorsal and ventral parts of the agranular insular cortex ipsilateral to the FG ejection. These results confirm previous findings that the anterior cingulate, prelimbic, and orbital cortices moderately innervate the anterior claustrum (Beckstead, 1979; Reep et al., 1996; Levesque and Parent, 1998) and that PHA-L ejection into the infralimbic cortex resulted in a modest labeling in the anterior claustrum (Takagishi and Chiba, 1991).

Caudal to the prefrontal cortex, a continuum of a moderate concentration of retrogradely labeled neurons in layer $\mathrm{V}$ stretched throughout the rostrocaudal extent of the ipsilateral secondary motor cortex and cingulate cortex, and retrograde labeling in the primary motor cortex remained modest (Fig. 5C). The contralateral secondary motor cortex and cingulate cortex were also modestly labeled. Farther caudally, a few labeled cells were detected in the anterior part of the retrosplenial agranular cortex ipsilaterally. This finding is not inconsistent with the previous finding that no labeled axons were detected in the claustrum after PHA-L ejection into the middle part of the retrosplenial agranular cortex (van Groen and Wyss, 1992a).

Caudal to the motor cortex, many labeled neurons were identified bilaterally in layers V and VI in the medial parts of both the 
Figure 5. Localization of FG immunoreactivity in rat 99143 . Representative bright-field microphotographs of coronal sections showing an ejection site that occupied the major part of the anterior claustrum $(A)$ and the distribution of FG-immunoreactive neurons in the orbital cortex $(B)$, motor and cingulate cortices $(C)$, middle part of the claustrum $(D)$, perirhinal cortex $(E)$, central part of the mediodorsal thalamic nucleus $(F)$, basolateral amygdaloid nucleus $(G)$, and substantia nigra $(H)$. The orientation of all images is such that the left side of the image is to the lateral side of the brain, right side to medial, and top side to dorsal. All other abbreviations are as indicated in previous figures. $S N$, Substantia nigra. Scale bars: $A, B, 435 \mu \mathrm{m} ; C-E, G, 174 \mu \mathrm{m} ; F$, $H, 87 \mu \mathrm{m}$.
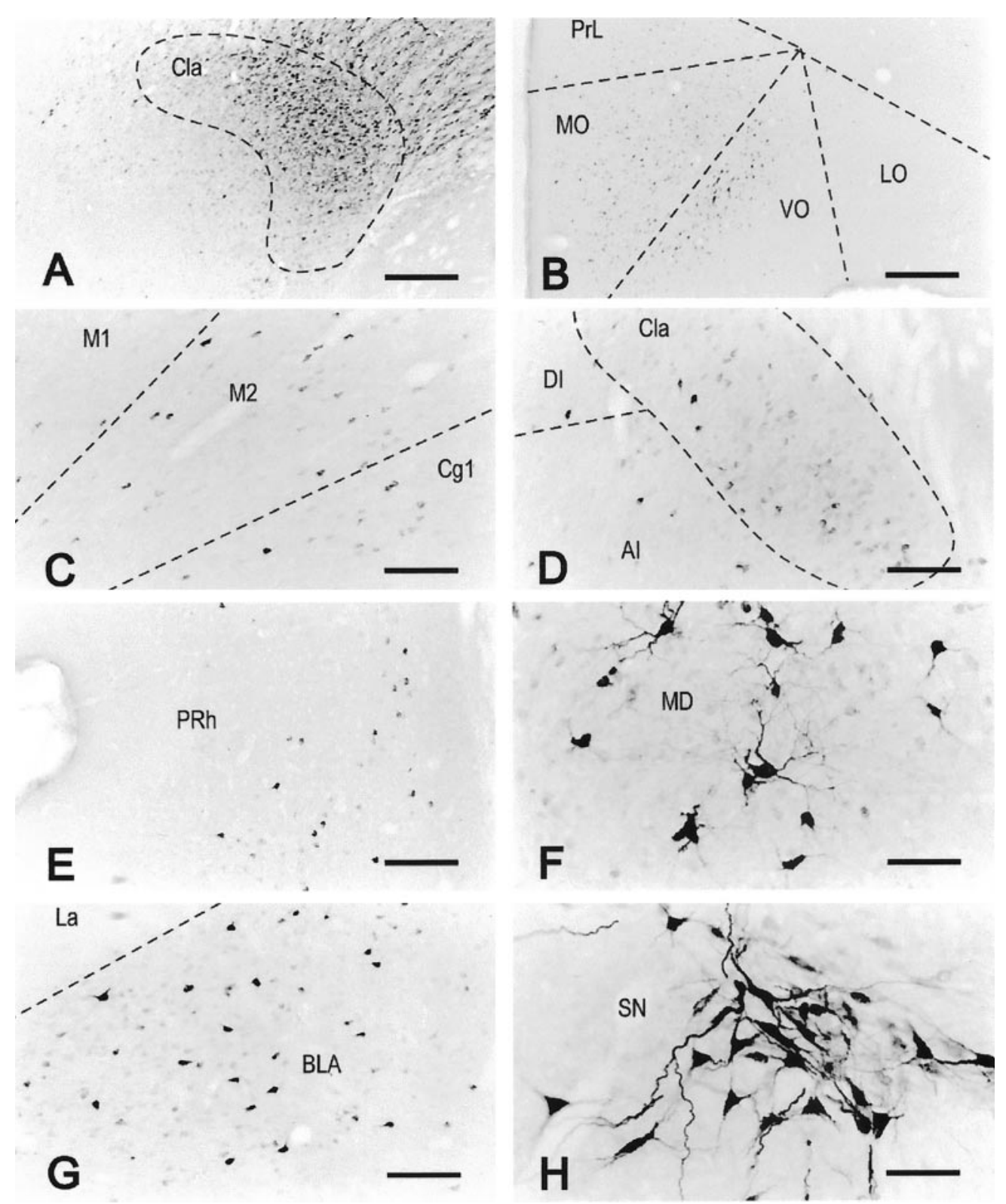

$F$

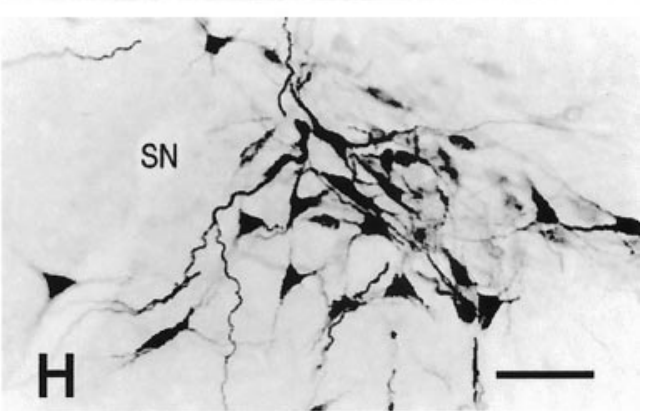

parietal association cortex and the secondary visual cortex, thus confirming the previous findings that deep neurons in area $18 \mathrm{~b}$ of the visual cortex directly innervate the anterior claustrum (Carey and Neal, 1985). Other areas of the parietal association cortex and visual cortex (including the lateral part of the secondary visual cortex and primary visual cortex) showed a modest labeling in layer VI. A similar pattern of retrograde labeling was also seen in the ipsilateral primary and secondary sensorimotor cortices and the auditory and temporal association cortices. Although the major part of the insular cortex contained a modest density of labeled cells, a high concentration of labeled neurons appeared in the contralateral anterior claustrum as well as in the entire extent of the ipsilateral claustrum at middle and posterior parts (Fig. $5 D$ ).

Caudal to the insular cortex, many labeled cells were distributed throughout the entire extent of the ectorhinal and perirhinal cortices (predominantly in layer $\mathrm{V}$ ), with moderate to high concentrations ipsilaterally (Fig. $5 E$ ) and a modest concentration contralaterally. Although a few labeled cells could be seen in the medial entorhinal cortex, moderate to high densities of labeled cells were present in the lateral entorhinal cortex ipsilaterally. This observation is generally consistent with the results of previous PHA-L studies (Swanson and Kohler, 1986; Insausti et al., 1997).

Clusters of retrogradely labeled neurons were seen in many midline and intralaminar thalamic nuclei ipsilateral to the FG ejection. Thus moderate to high concentrations of cell labeling appeared in the paracentral nucleus, middle and posterior parts of the paraventricular nucleus, central part of the mediodorsal nucleus (Fig. $5 F$ ), intermediodorsal nucleus, central medial nucleus, dorsal part of the centrolateral nucleus, reuniens nucleus, parafascicular nucleus, and zona incerta. A modest density of labeled cells was also present in the paratenial nucleus, anterior part of the paraventricular nucleus, rhomboid nucleus, ventromedial nucleus, dorsal and ventral parts of the submedius nucleus, and posterior nucleus. We could not identify any retrogradely labeled neurons in the ventrolateral, ventroposterior, laterodorsal, and lateroposterior thalamic nuclei, medial geniculate nu- 

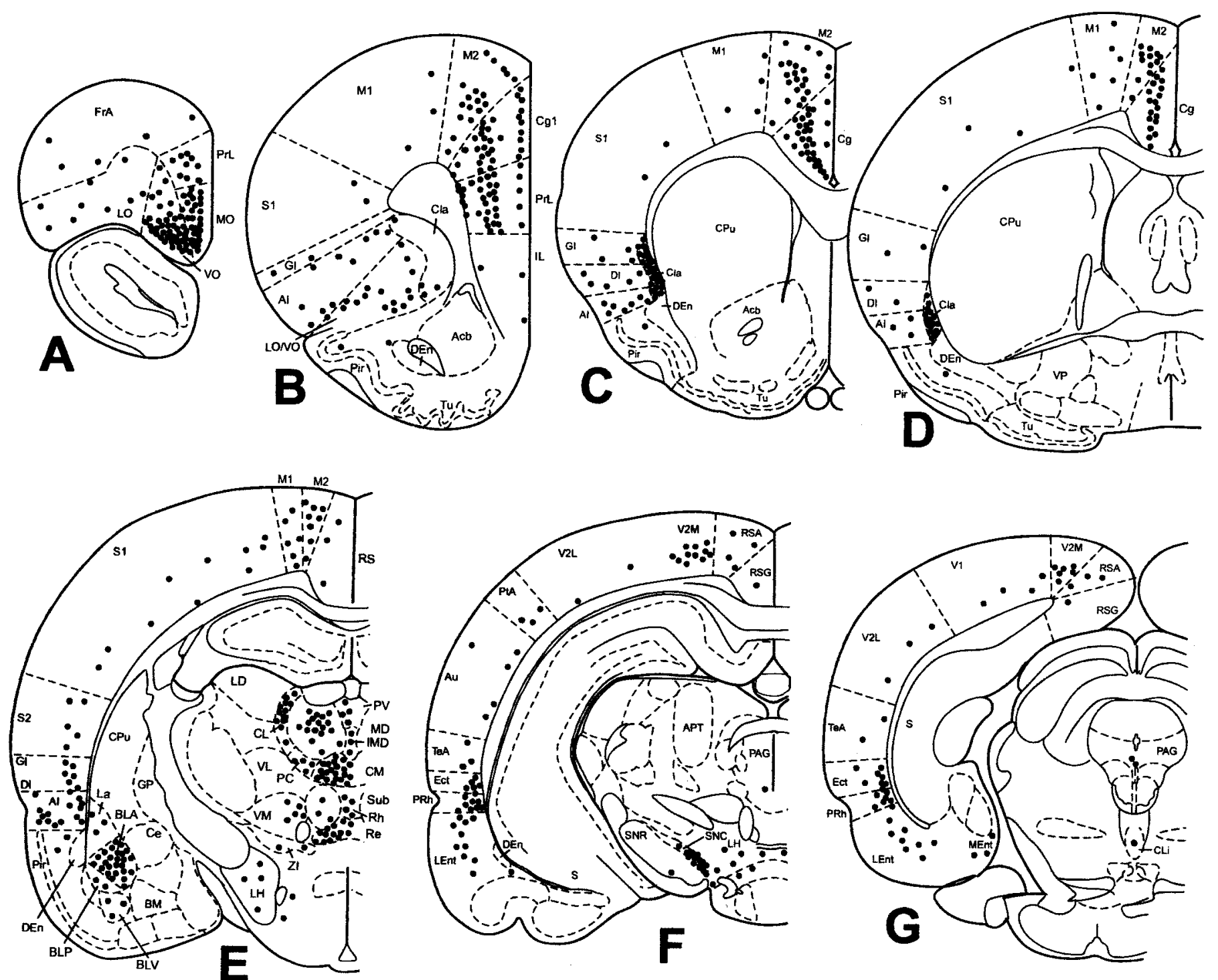

Figure 6. Afferent connections of the anterior claustrum in rat 99143. The distribution of FG-immunoreactive cells was plotted onto a series of standard drawings of the rat brain (Paxinos and Watson, 1998) at the same levels as in Figure 4. The dark gray area in $B$ indicates the ejection site, which is illustrated in Figure 5A. See Results for a more complete account of the contralateral afferent connections. For abbreviations, see previous figures.

cleus, and the anterior pretectal region, in contrast to the report of Sloniewski et al. (1986a), who used the retrograde tract-tracing agents Fast Blue and Diamidino Yellow. Moreover, the number of labeled cells in the posterior thalamic nucleus in our present study appears to be much less than that shown by Sloniewski et al. (1986a). These discrepancies could be explained by differences in the tract-tracing properties of FG as compared with Fast Blue or Diamidino Yellow. That is, injections of both Fast Blue and Diamidino Yellow usually produce tissue damage in the injection site (Schmued and Fallon, 1986; Sloniewski et al., 1986a), so that the tracers can be taken up by damaged fibers of passage (Schmued and Fallon, 1986), whereas FG appears not to be taken up by fibers of passage at the ejection site, as shown by the present results (see control ejections below) as well as previous studies (Schmued and Fallon, 1986; Pieribone and Aston-Jones, 1988; Chen and Su, 1990; Moga and Moore, 1997). In addition, FG does not leak out of labeled cells (Schmued and Fallon, 1986) and thus differs from Fast Blue and Diamidino Yellow, which can diff use out of labeled cells (Schmued and Fallon, 1986). These arguments and our present results are further supported by recent studies showing that although PHA-L ejections into the laterodorsal thalamic nucleus (van Groen and Wyss, 1992b) produced no anterograde labeling in the anterior claustrum, localized PHA-L ejection into other midline and intralaminar thalamic nuclei (such as the paraventricular nucleus) resulted in varying degrees of labeling in the anterior claustrum (Ohtake and Yamada, 1989; Berendse and Groenewegen, 1991; Moga et al., 1995).

Ventral to the thalamus, the lateral hypothalamic area also contained a low density of labeled neurons, whereas the other hypothalamic regions were devoid of FG labeling. In the brain stem, two populations of neurons ipsilateral to the FG ejection site were heavily stained, including neurons in the ventral part of the ventral tegmental area and the medial part of the substantia nigra pars compacta (Fig. 5H). This is consistent with previous findings that dopaminergic neurons in the ventral tegmental area and substantia nigra heavily innervate the anterior claustrum (Lindvall et al., 1978; Bjorklund and Lindvall, 1984). The parabrachial nucleus exhibited a modest level of FG labeling, thus 
confirming the results of a recent PHA-L study (Krukoff et al., 1993). The ipsilateral dorsal raphe nucleus contained a moderate concentration of neuronal labeling in the dorsal and ventrolateral parts, which is supported by previous PHA-L results indicating that the dorsal raphe nucleus innervates the entire claustrum (Vertes, 1991).

In addition to the FG ejections that were restricted to the anterior claustrum, we also obtained five ejections localized in regions adjacent to the anterior claustrum. The results of these experiments need to be commented on, because they serve as control ejections and support the specificity of the results of our analysis of the connections of the anterior claustrum. When FG was injected into the white matter mediodorsal to the anterior claustrum (i.e., the forceps minor corpus callosum) in one rat, no specific retrograde labeling was detected in the forebrain. This confirms the previous observation that FG appears not to be taken up by fibers of passage at the ejection site (Schmued and Fallon, 1986) and strongly suggests that our FG ejection centered within the anterior claustrum resulted in a specific retrograde labeling of neurons. In one rat that displayed a prominent extension of the FG ejection from the anterior claustrum caudally into the anterior caudate putamen, we observed a moderate labeling of pyramidal cells in the subicular complex in the ipsilateral hippocampal formation. We believe that this labeling probably results from the spread of the FG ejection into the anterior caudate putamen because one rat with FG ejection localized entirely in the anterior caudate putamen exhibited a similar pattern of retrograde labeling in the ipsilateral subicular complex, thus confirming the previous finding that neurons in the rat subiculum complex innervate the caudate putamen (Heimer et al., 1995). Furthermore, we could not identify any positive labeling in the subicular complex in four rats with FG ejections restricted to the anterior claustrum, consistent with the observations that ejection of PHA-L (van Groen and Wyss, 1990b) or other tract tracers (Swanson, 1981; Jay et al., 1989) revealed a substantial projection from the subicular and CA1 fields to the medial prefrontal cortex but not to the anterior claustrum. In two other rats with FG ejections located in areas ventral to the anterior claustrum (i.e., the ventral or lateral orbital cortex), the pattern of labeling was quite different from that produced by FG ejections centered in the anterior claustrum. Thus although no specific labeling could be detected in the piriform cortex and dorsal endopiriform nucleus after FG ejection into the anterior claustrum, FG ejection into the orbital cortex resulted in clear retrograde labeling in the ipsilateral piriform cortex and the dorsal endopiriform nucleus. This observation is consistent with the results of retrograde and anterograde tracing studies (Reep et al., 1996; Behan and Haberly, 1999).

\section{DISCUSSION}

The present study provides the first description of the characteristics of kindling from the anterior claustrum in rats. Anterior claustrum kindling is generally similar to kindling from the posterior claustrum, as we described previously (Mohapel et al., 1998, 1999). Both parts of the claustrum display greater sensitivity to kindling than the amygdala, to a degree comparable to the perirhinal cortex (McIntyre et al., 1993; Kelly and McIntyre, 1996).

We have also provided the first detailed description of the efferent and afferent connections of the anterior claustrum in rats. We found widespread and robust reciprocal connections between the anterior claustrum and many cortical and subcortical struc- tures that have been reported to play an important role in epileptiform activity.

\section{Anterior claustrum kindling}

We have reported previously (Mohapel et al., 1998, 1999) that the posterior claustrum, like the perirhinal cortex, is extremely susceptible to kindling and shows a two-phase progression through stage 5 seizures: an early phase characterized by rapid onset and short seizure durations, and a late phase virtually identical to limbic stage 5 seizures, with longer onset and duration of seizures. The present results confirm our prediction that the anterior claustrum is also susceptible to kindling, displaying a pattern and profile of kindling similar to that of the posterior claustrum.

The rapid kindling rates and brief latencies to clonus associated with perirhinal kindling have been cited as evidence for the critical involvement of perirhinal cortex in seizure generalization (McIntyre et al., 1993; Kelly and McIntyre, 1996). The common characteristics of kindling from perirhinal cortex, insula, and posterior claustrum suggest that similar considerations apply to the latter two structures (Mohapel et al., 1998, 1999), and the present results suggest further that the anterior claustrum may also play an important role in seizure generalization. Thus we propose the hypothesis that a set of anatomically interrelated structures in the forebrain, including anterior and posterior claustrum, insular cortex, and perirhinal cortex, play a key role in enabling epileptiform activity to access the motor substrates that support generalized seizures, substrates that at least in part are located in frontal and motor cortex. The fact that stimulation of claustrum or perirhinal cortex produces more rapid kindling than focal stimulation of frontal/motor cortex itself (Seidel and Corcoran, 1986) presumably reflects the broad anatomical connections of claustrum (present results) and perirhinal cortex (McIntyre et al., 1996) with cortex and other structures, which would allow widespread recruitment of discharge throughout the network. In support of this hypothesis, bilateral frontal lesions damaging the insula, orbital cortex, and anterior portions of the perirhinal cortex retard amygdaloid kindling (Corcoran et al., 1976), as do small bilateral lesions of the claustrum (Mohapel et al., 2001).

Notwithstanding the general similarities in the profiles of kindling from the insular cortex, perirhinal cortex, and claustrum, we note that there are some differences. By suspending rats in a harness during kindling, we were able to detect subtle differences in convulsions (Mohapel et al., 1999), including more rapid and more vigorous forelimb clonus in seizures kindled from posterior claustrum than in seizures from perirhinal or insular cortex. In future studies it will be important to examine anterior claustrum kindling in suspended rats. Furthermore, kindling from anterior and posterior claustrum is extremely rapid ("early kindling": anterior claustrum, 3.0 ADs, and posterior claustrum, 2.5 ADs; "late kindling: anterior claustrum, 9.3 ADs, and posterior claustrum, 13.7 ADs), and somewhat faster than from perirhinal cortex, insular cortex, or other limbic sites (Mohapel et al., 1999). It remains to be explored whether these differences reflect different functions or merely differences in density of connections.

\section{Efferent projections and their association with epilepsy}

Our results indicate that the anterior claustrum projects extensively to the frontal cortex of the rat, including motor cortex, orbital cortex, and insular cortex. These cortical structures are thought to play an important role in epileptogenesis (Corcoran et al., 1976; Wada and Wake, 1977; Kelly and McIntyre, 1996). In 
addition, we observed projections to other areas thought to participate in epileptiform activity, including perirhinal cortex (McIntyre et al., 1993), entorhinal cortex (Savage et al., 1985), and piriform cortex (McIntyre and Plant, 1989; Löscher and Ebert, 1996). Widespread subcortical projections are also present, including projections to olfactory structures, the endopiriform nucleus, the shell of the nucleus accumbens, the amygdala, and the midline thalamus, particularly the submedius nucleus. The sensitivity of the amygdala to epileptiform activity is well know, and recent data have implicated the endopiriform nucleus in epileptogenesis (Hoffman and Haberly, 1996) as well. One unanticipated finding was the strong projection to the submedius nucleus. This structure plays a role in nociception (Roberts and Dong, 1994); its functional involvement in claustrum kindling remains to be examined. The anterior claustrum also projects to brainstem structures, including the substantia nigra, the periaqueductal gray, and the dorsal raphe nucleus. The substantia nigra pars reticulata has been implicated in seizure susceptibility (Iadarola and Gale, 1982), as has the serotoninergic raphe system (Wada et al., 1997).

\section{Afferent connections}

FG ejections revealed widespread afferent projections to the anterior claustrum that largely, although not completely, reciprocate the efferent connections of the claustrum. We observed significant innervation from frontal, sensory, association, and limbic cortex, including ectorhinal, perirhinal, and lateral entorhinal cortex. There was some reciprocity of afferents with subcortical areas innervated by the anterior claustrum, including the midline thalamus, amygdala, medial substantia nigra, and dorsal raphe nucleus. Unexpectedly, however, significant afferent projections arise from the contralateral anterior claustrum and the entire extent of the middle and posterior ipsilateral claustrum.

The location of neurons in the medial prefrontal cortex (including secondary motor cortex, anterior part of area 1 of the cingulate cortex, prelimbic cortex, and infralimbic cortex) that innervate the anterior claustrum is similar to that of neurons in the medial prefrontal cortex, the axons of which join the corticospinal or pyramidal tract (Miller, 1987; Hurley et al., 1991). The corticospinal tract is known to collect axons from layer $\mathrm{V}$ pyramidal neurons in the primary motor and somatosensory cortices to innervate the "motor" nuclei in the brainstem and the spinal cord both in rats (Zilles 1990; Zilles and Wree, 1995) and in humans (Nolte, 1993; Brodal, 1998). Therefore, our observation of a corticoclaustrum projection from the medial prefrontal cortex may explain the involvement of the claustrum in coordination of sensorimotor or motor control (Olson and Graybiel, 1980; Crescimanno et al., 1989; Salerno et al., 1989; Cortimiglia et al., 1991; Shima et al., 1996), although it is unknown whether the same layer $\mathrm{V}$ neurons in the medial prefrontal cortex send axonal collaterals simultaneously joining the corticoclaustrum projection and corticospinal tract.

In a PHA-L study, McIntyre et al. (1996) demonstrated that one of the major efferent projections from the anterior perirhinal cortex in rats is the entire extent of the claustrum, a projection that appears to originate primarily from deep layers of the anterior perirhinal cortex. In addition to confirming these findings, the present study further demonstrated that a similar pattern of perirhinal-claustrum projection also exists in the middle and posterior parts of the perirhinal cortex as well as in the ectorhinal cortex as defined in atlases of the rat brain (Paxinos and Watson, 1998; Swanson, 1998). These results support the view that both the ectorhinal and perirhinal cortices located on the dorsal and ventral banks, respectively, of the rhinal fissure could be regarded neuroanatomically as a single structure, the perirhinal cortex (Burwell and Amaral, 1998).

Afferent projections to the anterior claustrum from the basolateral amygdaloid nucleus in rats were initially examined by Krettek and Price (1977a, 1978a) using tritiated amino acid as an anterograde tracer. They found that although the posterior part of the basolateral nucleus does not project to the entire anterocaudal extent of the claustrum, the anterior part of the basolateral nucleus heavily innervates the ipsilateral anterior claustrum but not the posterior claustrum. Our FG experiments showed, however, that neurons in the posterior part of the basolateral nucleus also project to the anterior claustrum, although the projection is much more modest than that from the anterior part of the basolateral nucleus. The discrepancy in results could result from a lower sensitivity of tritiated amino acids, because Kita and Kitai (1990), using the more sensitive anterograde tracing agent PHA-L, recently demonstrated a modest projection from the anterior part of the basolateral nucleus to the posterior claustrum.

In summary, significant afferent, efferent, or bidirectional projections exist between the anterior claustrum and various areas that have been implicated in epileptiform activity, including frontal and motor cortex, limbic cortex, amygdala, endopiriform nucleus, olfactory structures, nucleus accumbens, midline thalamus, and brainstem nuclei, including the substantia nigra and the dorsal raphe nucleus. The anatomical connections of the anterior claustrum are consistent with its very high susceptibility to kindling, as demonstrated here, and they support the view that the claustrum is part of a forebrain network of structures that participate in the generalization of seizures.

\section{REFERENCES}

Bayer SA, Altman J (1991) Development of the endopiriform nucleus and the claustrum in the rat brain. Neuroscience 45:391-412.

Bayer SA, Altman J, Russo RJ, Zhang X (1993) Timetables of neurogenesis in the human brain based on experimentally determined patterns in the rat. Neurotoxicology 14:83-144.

Beck CHM, Fibiger HC (1995) Conditioned fear-induced changes in behavior and in the expression of the immediate early gene c-fos: with and without diazepam pretreatment. J Neurosci 15:709-720.

Beckstead RM (1979) An autoradiographic examination of corticocorti$\mathrm{cal}$ and subcortical projections of the mediodorsal-projection (prefrontal) cortex in the rat. J Comp Neurol 184:43-61.

Behan M, Haberly LB (1999) Intrinsic and efferent connections of the endopiriform nucleus in rat. J Comp Neurol 408:532-548.

Berendse HW, Groenewegen HJ (1991) Restricted cortical termination fields of the midline and intralaminar thalamic nuclei in the rat. Neuroscience 42:73-102.

Bjorklund A, Lindvall O (1984) Dopamine-containing systems in the CNS. In: Handbook of chemical neuroanatomy, classical transmitters in the CNS, Part I (Bjorklund A, Hokfelt T, eds), pp 55-122. Amsterdam: Elsevier.

Brodal P (1998) Cerebral cortex. In: The central nervous system, Ed 2 (Brodal P, ed), pp 583-620. New York: Oxford UP.

Brodmann K (1909) Vergleichende Lokalisationslehre der Grosshirnrinde. Barth: Leipzig.

Burwell RD, Amaral DG (1998) Cortical afferents of the perirhinal, postrhinal, and entorhinal cortices of the rat. J Comp Neurol 398:179-205.

Carey RG, Neal TL (1985) The rat claustrum: afferent and efferent connections with visual cortex. Brain Res 329:185-193.

Chen S, Su HS (1990) Afferent connections of the thalamic paraventricular and paratenial nuclei in the rat: a retrograde tracing study with iontophoretic application of Fluoro-Gold. Brain Res 522:1-6.

Clasca F, Avendano C, Roman-Guindo A, Llamas A, Reinoso-Suarez F (1992) Innervation from the claustrum of the frontal association and motor areas: axonal transport studies in the cat. J Comp Neurol 326:402-422.

Conde F, Maire-Lepoivre E, Audinat E, Crepel F (1995) Afferent connections of the medial frontal cortex of the rat. II. Cortical and subcortical afferents. J Comp Neurol 352:567-593. 
Corcoran ME, Urstad H, McCaughran JA, Wada JA (1976) Frontal lobe and kindling in rat. In: Kindling (Wada JA, ed), pp 215-228. New York: Raven.

Cortimiglia R, Crescimanno G, Salerno MT, Amato G (1991) The role of the claustrum in the bilateral control of frontal occulomotor neurons in the cat. Exp Brain Res 84:471-477.

Crescimanno G, Salerno MT, Cortimiglia R, Amato G (1989) Claustral influence on ipsi- and contralateral motor cortical areas, in the cat. Brain Res Bull 22:839-843.

Deacon TW, Eichenbaum H, Rosenberg P, Eckmann KW (1983) Afferent connections of the perirhinal cortex in the rat. J Comp Neurol 220:168-190.

Dinopoulos A, Papadopoulos GC, Michaloudi H, Parnavelas JG, Uylings HB, Karamanlidis AN (1992) Claustrum in the hedgehog (Erinaceus europaeus) brain: cytoarchitecture and connections with cortical and subcortical structures. J Comp Neurol 316:187-205.

Divac I, Kosmal A, Bjorklund A, Lindvall O (1978) Subcortical projections to the prefrontal cortex in the rat as revealed by the horseradish peroxidase technique. Neuroscience 3:785-796.

Donoghue JP, Parham C (1983) Afferent connections of the lateral agranular field of the rat motor cortex. J Comp Neurol 217:390-404.

Druga R (1972) Efferent projections from the claustrum (an experimental study using Nauta's method). Folia Morphol (Praha) 20:163-165.

Druga R (1982) Claustro-neocortical connections in the cat and rat demonstrated by HRP tracing technique. J Hirnforsch 23:191-202.

Druga R, Rokyta R, Benes V (1990) Claustro-neocortical projections in the rhesus monkey (projections to area 6). J Hirnforsch 31:487-494.

Filiminoff IN (1966) The claustrum, its origin and development. J Hirnforsch 8:503-528.

Gerfen CR, Sawchenko PE (1984) An anterograde neuroanatomical tracing method that shows the detailed morphology of neurons, their axons and terminals: immunohistochemical localization of an axonally transported plant lectin, Phaseolus vulgaris-leucoagglutinin. Brain Res 290:219-238

Groenewegen HJ (1988) Organization of the afferent connections of the mediodorsal thalamic nucleus in the rat, related to the mediodorsalprefrontal topography. Neuroscience 24:379-431.

Haberly LB, Price JL (1978) Association and commissural fiber systems of the olfactory cortex of the rat. I. Systems originating in the piriform cortex and adjacent areas. J Comp Neurol 178:711-740.

Heimer L, Zahm DS, Alheid GF (1995) Basal ganglia. In: The rat nervous system, Ed 2 (Paxinos G, ed), pp 579-628. San Diego: Academic.

Hoffman WH, Haberly LB (1996) Kindling-induced epileptiform potentials in piriform cortex slices originate in the underlying endopiriform nucleus. J Neurophysiol 76:1430-1438.

Hurley KM, Herbert H, Moga MM, Saper CB (1991) Efferent projections of the infralimbic cortex of the rat. J Comp Neurol 308:249-276.

Iadarola MJ, Gale K (1982) Substantia nigra: site of anticonvulsant activity mediated by gamma-aminobutyric acid. Science 218:1237-1240.

Insausti R, Herrero MT, Witter MP (1997) Entorhinal cortex of the rat: cytoarchitectonic subdivisions and the origin and distribution of cortical efferents. Hippocampus 7:146-183.

Jay TM, Glowinski J, Thierry A-M (1989) Selectivity of the hippocampal projection to the prelimbic area of the prefrontal cortex in the rat. Brain Res 505:337-340.

Kelly ME, McIntyre DC (1996) Perirhinal cortex involvement in limbic kindled seizures. Epilepsy Res 26:233-243.

Kelly ME, Battye RA, McIntyre DC (1999) Cortical spreading depression reversibly disrupts convulsive motor seizure expression in amygdala-kindled rats. Neuroscience 91:305-313.

Kita H, Kitai ST (1990) Amygdaloid projections to the frontal cortex and the striatum in the rat. J Comp Neurol 298:40-49.

Kolb B (1990) Prefrontal cortex. In: the cerebral cortex of the rat (Kolb B, Tees RC, eds), pp 437-458. Cambridge: MIT.

Kowianski P, Morys J, Dziewiatkowski J, Karwacki Z, Bobek-Billewicz B, Narkiewicz O (1996) Neurons of the claustrum projecting to the motor and somatosensory cortex in the rabbit: assessment with the method of retrograde transport of fluorescent tracers. Folia Morphol (Warsz) $55: 350-352$.

Kowianski P, Dziewiatkowski J, Berdel B, Lipowska M, Morys J (1998a) The corticoclaustral connections in the rat studied by means of the fluorescent retrograde axonal transport method. Folia Morphol (Warsz) 57:85-92.

Kowianski P, Morys J, Karwacki Z, Dziewiatkowski J, Narkiewicz O (1998b) The cortico-related zones of the rabbit claustrum study of the claustrocortical connections based on the retrograde axonal transport of fluorescent tracers. Brain Res 784:199-209.

Kowianski P, Dziewiatkowski J, Kowianski J, Morys J (1999) Comparative anatomy of the claustrum in selected species: a morphometric analysis. Brain Behav Evol 53:44-54.

Krettek TE, Price JL (1977a) Projections from the amygdaloid complex to the cerebral cortex and thalamus in the rat and cat. J Comp Neurol 172:687-722.

Krettek TE, Price JL (1977b) Projections from the amygdaloid complex and adjacent olfactory structures to the entorhinal cortex and to the subiculum in the rat and cat. J Comp Neurol 172:723-752.

Krettek TE, Price JL (1978a) Amygdaloid projections to the subcortical structures within the basal forebrain and brainstem in the rat and cat. J Comp Neurol 178:225-254.

Krettek TE, Price JL (1978b) A description of the amygdaloid complex in the rat and cat with observations on intra-amygdaloid axonal connections. J Comp Neurol 178:255-280.

Krukoff TL, Harris KH, Jhamandas JH (1993) Efferent projections from the parabrachial nucleus demonstrated with the anterograde tracer Phaseolus vulgaris leucoagglutinin. Brain Res Bull 30:163-172.

Kudo T, Wada JA (1990) Claustrum and amygdaloid kindling. In: Kindling 4 (Wada JA, ed), pp 397-408. New York: Plenum.

LeVay S, Sherk H (1981) The visual claustrum of the cat. I. Structure and connections. J Neurosci 1:956-980.

Levesque M, Parent A (1998) Axonal arborization of corticostriatal and corticothalamic fibers arising from prelimbic cortex in the rat. Cereb Cortex 8:602-613.

Lindvall O, Bjorklund A, Divac I (1978) Organization of catecholamine neurons projecting to the frontal cortex in the rat. Brain Res 142:1-24.

Löscher W, Ebert U (1996) The role of the piriform cortex in kindling. Prog Neurobiol 50:427-481.

Macchi G (1951) The ontogenetic development of the olfactory telencephalon in man. J Comp Neurol 95:245-305.

Markowitsch HJ, Irle E, Bang-Olsen R, Flindt-Egebak P (1984) Claustral efferents to the cat's limbic cortex studied with retrograde and anterograde tracing techniques. Neuroscience 12:409-425.

McIntyre DC, Plant JR (1989) Pyriform cortex involvement in kindling. Neurosci Biobehav Rev 13:277-280.

McIntyre DC, Kelly ME, Armstrong JN (1993) Kindling in the perirhinal cortex. Brain Res 615:1-6.

McIntyre DC, Kelly ME, Staines WA (1996) Efferent projections of the anterior perirhinal cortex in the rat. J Comp Neurol 369:302-318.

Meynert TH (1868) Neue Untersuchungen uber den Bau der Grobhirnrinde und ihre ortlichen Verschiedenheiten. All Wien Med Zeitung 13:419-428.

Miller MW (1987) The origin of corticospinal projection neurons in rat. Exp Brain Res 67:339-351.

Minciacchi D, Molinari M, Bentivoglio M, Macchi G (1985) The organization of the ipsi- and contralateral claustrocortical system in rat with notes on the bilateral claustrocortical projections in cat. Neuroscience 16:557-576

Moga MM, Moore RY (1997) Organization of neural inputs to the suprachiasmatic nucleus in the rat. J Comp Neurol 389:508-534.

Moga MM, Weis RP, Moore RY (1995) Efferent connections of the paraventricular thalamic nucleus in the rat. $\mathrm{J}$ Comp Neurol 359:221-238

Mohapel P, Chlan-Fourney J, Zhang X, Hannesson DK, Wallace A, Li XM, Corcoran ME (1998) Fos protein and BDNF mRNA changes following claustrum and deep perirhinal/insular kindling in the rat. Soc Neurosci Abstr 24:850.12.

Mohapel P, Hannesson DK, Corcoran ME (1999) Are the properties of perirhinal kindling unique to the perirhinal cortex? Soc Neurosci Abstr 25:217.8.

Mohapel P, Hannesson DK, Armitage LL, Gillespie GW, Corcoran ME (2001) Claustrum lesions delay amygdaloid kindling in the rat. Epilepsia, in press.

Morys J, Sloniewski P (1986) Projections of the claustrum to some areas of the neocortex in the rat: an HRP study. Folia Morphol (Warsz) 45:175-181.

Morys J, Narkiewicz O, Maciejewska B, Wegiel J, Wisniewski HM (1994) Amyloid deposits and loss of neurones in the claustrum of the aged dog. NeuroReport 5:1825-1828.

Morys J, Berdel B, Maciejewska B, Krol J, Dziewiatkowski J (1996a) Loss of neurons in the claustrum of aging brain. Folia Neuropathol 34:97-101.

Morys J, Bobinski M, Wegiel J, Wisniewski HM, Narkiewicz O (1996b) Alzheimer's disease severely affects areas of the claustrum connected with the entorhinal cortex. J Hirnforsch 37:173-180.

Nolte J (1993) Cerebral cortex. In: The human brain (Nolte J, ed), pp 360-390. St. Louis: Mosby.

Ogomori K, Kitamoto T, Tateishi J, Sato Y, Suetsugu M, Abe M (1989) Beta-protein amyloid is widely distributed in the central nervous system of patients with Alzheimer's disease. Am J Pathol 134:243-251.

Ohtake T, Yamada H (1989) Efferent connections of the nucleus reuniens and the rhomboid nucleus in the rat: an anterograde PHA-L tracing study. Neurosci Res 6:556-568.

Olson CR, Graybiel AM (1980) Sensory maps in the claustrum of the cat. Nature 288:479-481.

Paxinos G, Watson C (1998) The rat brain in stereotaxic coordinates, Ed 4. New York: Academic.

Pelletier MR, Corcoran ME (1992) Intra-amygdaloid infusions of clonidine retard kindling. Brain Res 598:51-58.

Pelletier MR, Corcoran ME (1993) Inf usions of alpha-2 adrenergic ago- 
nists and antagonists into the amygdala: effects on kindling. Brain Res 632:29-35.

Persinger MA, Peredery O, Bureau YR, Cook LL (1997) Emergent properties following brain injury: the claustrum as a major component of a pathway that influences nociceptive thresholds to foot shock in rats. Percept Mot Skills 85:387-398.

Pieribone VA, Aston-Jones G (1988) The iontophoretic application of Fluoro-Gold for the study of afferents to deep brain nuclei. Brain Res 475:259-271.

Racine RJ (1972) Modification of seizure activity by electrical stimulation. II. Motor seizure. Electroencephalogr Clin Neurophysiol 32:281-294.

Reep RL, Corwin JV, King V (1996) Neuronal connections of orbital cortex in rats: topography of cortical and thalamic afferents. Exp Brain Res 111:215-232.

Roberts VJ, Dong WK (1994) The effect of thalamic nucleus submedius lesions on nociceptive responding in rats. Pain 57:341-349.

Sadowski M, Morys J, Jakubowska-Sadowska K, Narkiewicz O (1997a) Rat's claustrum shows two main cortico-related zones. Brain Res 756:147-152.

Sadowski M, Morys J, Jakubowska-Sadowska K, Narkiewicz O (1997b) Some claustral neurons projecting to various neocortical areas show morphological differences. Folia Morphol (Warsz) 56:65-76.

Salerno MT, Cortimiglia R, Crescimanno G, Amato G (1989) Effect of claustrum activation on the spontaneous unitary activity of frontal eye field neurons in the cat. Neurosci Lett 98:299-304.

Savage DD, Rigsbee LC, McNamara JO (1985) Knife cuts of entorhinal cortex: effects on development of amygdaloid kindling and seizureinduced decrease of muscarinic cholinergic receptors. J Neurosci 5:408-413.

Schmued LC, Fallon JH (1986) Fluoro-Gold: a new fluorescent retrograde axonal tracer with numerous unique properties. Brain Res 377:147-154.

Seidel WT, Corcoran ME (1986) Relations between amygdaloid and anterior neocortical kindling. Brain Res 385:375-378.

Sherk H (1988) The claustrum and the cerebral cortex. In: Cerebral cortex, Vol 5. Sensory-motor areas and aspects of cortical connectivity (Jones EG, Peters A, eds), pp 467-499. New York: Plenum.

Shima K, Hoshi E, Tanji J (1996) Neuronal activity in the claustrum of the monkey during performance of multiple movements. J Neurophysiol 76:2115-2119.

Sloniewski P, Pilgrim C (1984) Claustro-neocortical connections in the rat as demonstrated by retrograde tracing with Lucifer yellow. Neurosci Lett 49:29-32.

Sloniewski P, Usunoff KG, Pilgrim C (1986a) Diencephalic and mesencephalic afferents of the rat claustrum. Anat Embryol (Berl) 173:401-411.

Sloniewski P, Usunoff KG, Pilgrim C (1986b) Retrograde transport of fluorescent tracers reveals extensive ipsi- and contralateral claustrocortical connections in the rat. J Comp Neurol 246:467-477.

Sloniewski P, Morys J, Pilgrim C (1995) Stimulation of glucose utilization in the rat claustrum by pain. Folia Neuropathol 33:163-168.

Swanson LW (1981) A direct projection from Ammons horn to prefrontal cortex in the rat. Brain Res 217:150-154.

Swanson LW (1998) Brain maps: structure of the rat brain. Amsterdam: Elsevier.

Swanson LW, Kohler C (1986) Anatomical evidence for direct projec- tions from the entorhinal area to the entire cortical mantle in the rat. J Neurosci 6:3010-3023.

Takagishi M, Chiba T (1991) Efferent projections of the infralimbic (area 25) region of the medial prefrontal cortex in the rat: an anterograde tracer PHA-L study. Brain Res 566:26-39.

van Groen T, Wyss JM (1990a) Connections of the retrosplenial granular cortex in the rat. J Comp Neurol 300:593-606.

van Groen T, Wyss JM (1990b) Extrinsic projections from area CA1 of the rat hippocampus: olfactory, cortical, subcortical, and bilateral hippocampal formation projections. J Comp Neurol 302:515-528.

van Groen T, Wyss JM (1992a) Connections of the retrosplenial dysgranular cortex in the rat. J Comp Neurol 315:200-216.

van Groen T, Wyss JM (1992b) Projections from the laterodorsal nucleus of the thalamus to the limbic and visual cortices in the rat. J Comp Neurol 324:427-448.

Vertes RP (1991) A PHA-L analysis of ascending projections of the dorsal raphe nucleus in the rat. J Comp Neurol 313:643-668.

Wada JA, Kudo T (1997) Involvement of the claustrum in the convulsive evolution of temporal limbic seizure in feline amygdaloid kindling. Electroencephalogr Clin Neurophysiol 103:249-256.

Wada JA, Tsuchimochi H (1997) Role of the claustrum in convulsive evolution of visual afferent and partial nonconvulsive seizure in primates. Epilepsia 38:897-906.

Wada JA, Wake A (1977) Dorsal frontal, orbital and mesial frontal cortical lesion and amygdaloid kindling in cats. Can J Neurol Sci 2:107-115.

Wada Y, Shiraishi J, Nakamura M, Koshino Y (1997) Role of serotonin receptor subtypes in the development of amygdaloid kindling in rats. Brain Res 747:338-342.

Wilhite BL, Teyler TJ, Hendricks C (1986) Functional relations of the rodent claustral-entorhinal-hippocampal system. Brain Res 365:54-60.

Witter MP, Room P, Groenewegen HJ, Lohman AH (1988) Reciprocal connections of the insular and piriform claustrum with limbic cortex: an anatomical study in the cat. Neuroscience 24:519-539.

Yoshida A, Dostrovsky JO, Chiang CY (1992) The afferent and efferent connections of the nucleus submedius in the rat. J Comp Neurol 324:115-133.

Yoshimura N, Yoshimura I, Asada M, Hayashi S, Fukushima Y, Sato T, Kudo H (1988) Juvenile Parkinson's disease with widespread Lewy bodies in the brain. Acta Neuropathol (Berl) 77:213-218.

Zald DH, Pardo JV (1999) The functional neuroanatomy of voluntary swallowing. Ann Neurol 46:281-286.

Zhang X, Boulton AA, Yu PH (1996) Expression of heat shock protein-70 and limbic seizure-induced neuronal death in the rat brain. Eur J Neurosci 8:1432-1440.

Zhang X, Le Gal La Salle G, Ridoux V, Yu PH, Ju G (1997a) Prevention of kainic acid-induced limbic seizures and Fos expression by GABA-A receptor agonist muscimol. Eur J Neurosci 9:29-40.

Zhang X, Gelowitz DL, Lai CT, Boulton AA, Yu PH (1997b) Gradation of kainic acid-induced rat limbic seizures and expression of hippocampal heat shock protein-70. Eur J Neurosci 9:760-769.

Zilles K (1990) Anatomy and the neocortex: cytoarchitecture and myeloarchitecture. In: The cerebral cortex of the rat (Kolb B, Tees RC, eds), pp 77-112. Cambridge: MIT.

Zilles K, Wree A (1995) Cortex: areal and laminar structure. In: The rat nervous system, Ed 2 (Paxinos G, ed), pp 649-687. San Diego: Academic. 